\title{
IMPACTO DEL PROGRAMA DE LA COOPERACIÓN ESPAÑOLA EN LA PUESTA EN VALOR DEL PATRIMONIO EN EL CENTRO HISTÓRICO DE LIMA $[1990-2013]^{(*)}$
}

\author{
IMPACT OF THE SPANISH COOPERATION PROGRAM ON HERITAGE REVALUATION IN THE \\ HISTORIC CENTER OF LIMA [1990-2013]
}

\author{
JARIM MELGAR MONTES ${ }^{[\star ⿱ 亠 乂}$ \\ Universidad Nacional de Ingeniería (Perú) \\ jarimelgar@gmail.com
}

Fecha de recepción: 01 de setiembre de 2017

Fecha de aprobación: 02 de octubre de 2018

\begin{abstract}
RESUMEN
En la década de 1990, se vivió en Perú una crisis nacional producto de la violencia en el país y el decrecimiento de la economía. Es en este contexto que el programa Patrimonio para el Desarrollo de la Cooperación Española inició sus labores en el Centro Histórico de Lima. En un panorama en el que la prioridad no es la intervención en bienes culturales, surgió un proyecto que busca suplir diferentes necesidades en la sociedad a través de la puesta en valor del patrimonio. Por medio del proceso de recuperación se intentó instruir a las personas en el oficio del restauro, para que luego puedan integrar al proyecto. El programa entonces tenía como objetivo la recuperación del patrimonio, y con la creación de la Escuela Taller de Lima se esperaba capacitar a la población para realizar los trabajos de restauración y conservación. Al introducir la Escuela Taller como parte del programa se incluyeron la dimensión social y la económica en una relación bilateral entre Perú y España que antes fue mayoritariamente de carácter cultural.
\end{abstract}

\section{PALABRAS CLAVE}

Patrimonio, Centro Histórico de Lima, Cooperación Española

\begin{abstract}
In the decade of 1990, Peru lived through a national crisis, a result of the violence in the country and the decrease in the growth of the economy. In this context, the program Heritage for Development of the Spanish Cooperation began its work in the Historic Center of Lima. In a situation in which the priority is not the intervention in cultural assets, a project emerged that seeks to meet society's different needs through the revaluation of the patrimony. Through this recovery process, there were attempts to instruct people in the craft of restoration, in order to later on include them in the project. The goal of the program at the time was the restoration of heritage and, with the creation of the Escuela Taller de Lima, the project expected to train the population in restoration and conservation work. When the Escuela Taller was introduced as part of the program, it included the social and economic dimension in a bilateral relationship between Peru and Spain, which was mostly cultural in the past
\end{abstract}

\section{KEYWORDS}

Heritage, Historic Center of Lima, Spanish Cooperation

$\left(^{*}\right)$ El presente artículo es una síntesis del trabajo de investigación realizado en la asignatura Taller de Investigación en Historia de la Arquitectura (THIS) del pregrado de la Facultad de Arquitectura, Urbanismo y Artes de la Universidad Nacional de Ingeniería (FAUA-UNI). Dicha investigación se inició en las asignaturas de THIS 1 (ciclo 2016-I), bajo la responsabilidad del Prof. MSc. Arq. José Beingolea Del Carpio, y se concluyó en el THIS 2 (ciclo 2016-II), siendo docentes el Prof. Arq. José Correa Orbegoso y el Prof. MSc. Arq. José Hayakawa Casas. $\left.{ }^{* *}\right)$ Estudiante de Arquitectura del décimo ciclo de la FAUA-UNI. Experiencia como asistente del curso de restauración de monumentos de la FAUA-UNI, a cargo de los profesores Arq. José Correa y Arq. Carlos Díaz (ciclos 2014-I y 2014-II) y del Taller SFM: Registro de Bajo Costo para el Patrimonio Edificado, bajo la responsabilidad del Prof. MSc. Arq. José Hayakawa (2018). 
devenir Vol. 5, N¹0, JULIO-DICIEMBRE 2018, pP. 109-134 - EstudIOS I ISSN 2312-7562 | E-ISSN 2616-4949

UNIVERSIDAD NACIONAL DE INGENIERÍ, LIMA

DOI: https://doi.org/10.21754/devenir.v5i10.601

\section{Fundación de la ciudad de Lima e independencia}

El primer encuentro entre Perú y España se produjo en 1532, cuando arribó a Cusco Francisco Pizarro, junto a 160 soldados españoles. Tres años después llegó a Lima:

La fundación española de Lima se realizó frente al palacio de Taulichusco, con su consentimiento, el 18 de enero de 1535. Allí se clavó la picota o madera de ajusticiamiento y Pizarro entregó solares a los conquistadores nombrando al cabildo que gobernaría la ciudad (Gunther, 1992, p. 9).

A la fundación le siguió la etapa virreinal. Lima empezó con una trama urbana cuadricular conocida hoy como el Damero de Pizarro; posteriormente, le siguió la construcción de las murallas en 1686; casi dos siglos después, en 1860, se decidió demoler las murallas para continuar con la expansión de la ciudad. El dominio de la Corona española continuaría hasta el 28 de julio de 1821, cuando el general don José de San Martín proclamó la Independencia del Perú. Este hecho fue el inicio de un largo proceso de desocupación del territorio peruano de parte de las tropas españolas, que se consumó el 22 de enero de 1826, casi cinco años después.

\section{Construcción de las relaciones entre Estados}

El primer acercamiento entre ambas naciones ocurrió en 1839, cuando el Gobierno peruano decidió autorizar la apertura de los puertos a embarcaciones españolas. Sobre este hecho, Arturo García Salazar afirma que "considerando que la nación española y su gobierno habían dado pruebas de estar resueltos a reconocer la independencia del Perú, se decide abrir los puertos a los buques españoles en los mismos términos que los de otras naciones europeas" (como se citó en Novak, 2001, p. 28).

Sin embargo, no fue hasta 1853 que se logró el primer acercamiento diplomático (durante los gobiernos del general José Rufino Echenique y la Reina Isabel II), para suscribir el primer Tratado de Paz y Amistad entre ambos países. Lamentablemente, el tratado no llegó a ser ratificado debido a discrepancias en torno a la redacción del mismo. Este fracaso trajo consigo el enfriamiento de las relaciones bilaterales, las cuales se intentó retomar en 1855, sin éxito alguno. El estado de abandono y degradación de las relaciones dio paso a una total ruptura cuando se desató el conflicto bélico hispano-sudamericano en 1865, que involucró a España, y al eje aliado formado por Perú, Chile, Ecuador y Bolivia.

Finalmente, el 14 de agosto de 1879, se firmó el Tratado de Paz y Amistad en la ciudad de París, mediante el cual se decidió unánimemente olvidar lo acontecido durante la guerra e iniciar así de manera formal las relaciones diplomáticas entre el Perú y España. Durante los años posteriores se suscribieron los primeros acuerdos internaciones entre ambos países. Las relaciones fueron mejorando, e incluso Perú llegó a solicitar la ayuda de España

para dar solución a sus problemas limítrofes con Ecuador y Chile, Perú recurrió al arbitraje de la Corona Española. Las disputas que caracterizaron el primer período de nuestras relaciones habían quedado definitivamente zanjadas. Nuestro País confiaba nada menos que su integridad territorial a la decisión del monarca español, en una muestra de que nuestras relaciones con España habían emprendido un nuevo camino. (Novak, 2001, pp. 303-304)

El 31 de enero de 1924 se inició un proceso de cooperación militar. Luego, el 26 de febrero del mismo año, comenzó la primera relación, en cuanto a políticas culturales se refiere, al suscribirse el Tratado sobre Propiedad Literaria y Artística. Este acuerdo, que se ratificó al cabo de cuatro años, señala en su primer artículo la protección de la propiedad intelectual de los autores de ambos países. En 1925, el Gobierno peruano se comprometió a participar en la Exposición Iberoamericana de Sevilla; así, el 9 de mayo de 1929 se inauguró allí el pabellón de Perú, construido por Manuel Piqueras Cotolí. 
La segunda etapa de cooperación relacionada a temas culturales comenzó en 1943, tras el incendio de la Biblioteca Nacional del Perú. Fue entonces que el Gobierno español organizó colectas de libros para ser remitidos a Lima. Dos años más tarde, se aprobó un crédito extraordinario de 40 millones de pesetas para favorecer la expansión cultural de España en América.

En esos momentos, la imagen internacional de España se vio deteriorada por la afinidad que el régimen del general Francisco Franco (1939-1975) mantuvo con las potencias del Eje durante la Segunda Guerra Mundial, razón por la cual su ingreso a la Organización de las Naciones Unidas (ONU) fue denegado. En ese contexto, se creó en España el Instituto de Cultura Hispánica (ICH), con el fin de reforzar los vínculos culturales con Hispanoamérica, y contar así con apoyo para levantar su veto en la ONU. El ICH logró su objetivo en 1950, cuando sucedió lo siguiente:

Los delegados de la República Dominicana, El Salvador y Perú presentaron en la ONU una resolución para que se levantaran las sanciones a España, que fue aprobada con los votos favorables del resto de los países hispanoamericanos, a los que se unieron el bloque árabe y los Estados Unidos. Cinco años más tarde, en diciembre de 1955, España era por fin aceptada en las Naciones Unidas. (Navarro, 2011, p. 44)

En 1959 se celebró el Convenio de Doble Nacionalidad, el cual tuvo como objetivo fortalecer los vínculos entre Perú y España. Ese mismo año se decidió suprimir el requerimiento de visado para movilizarse entre ambos países. En 1964 se realizó el censo de estudiantes universitarios en España, el cual, en sus resultados, arrojó un total de 1,081 peruanos. Sin embargo, considerando la tasa de ausentismo, se calcula que el total real sería de aproximadamente 2,000 estudiantes. Hacia 1967, el número ascendía a 2,320. Un año después llegó al Perú una misión científica procedente de España, específicamente a Cuzco, con la intención de realizar una serie de investigaciones sobre los complejos arqueológicos incaicos ubicados en los pueblos de Chincheros y de Umasbamba. En 1977 se reafirmó la política exterior de España, al establecer "vínculos fraternales y de cooperación con Iberoamérica teniendo como base la historia y la cultura común" (Novak, 2001, p. 159).

Según Novak (2001), la nueva etapa iniciada en 1975 con el fin del franquismo en España y la culminación del primer gobierno de Alan García en Perú en 1990 se caracterizó por el énfasis puesto en la cooperación técnica y financiera de España hacia Perú. En esta etapa fueron innumerables los acuerdos de cooperación en materia técnica, social, cultural y financiera que se celebraron entre los dos países, a pesar de la crisis económica y del impacto negativo del terrorismo en el Perú. Sin embargo, más allá de la cooperación, lo cierto es que el progresivo deterioro de la imagen del Perú en el exterior se agravó debido al aislamiento económico y financiero, a la ausencia de seguridades para la inversión y al incremento del fenómeno subversivo, lo cual impidió que las relaciones con España abarcaran el ámbito comercial y la inversión de capitales. Cabe destacar, de manera independiente, la cooperación cultural. Durante este periodo sobresalieron los actos realizados en celebración de los 450 años de la fundación de Lima, evento que tuvo gran difusión en España. Para esta ocasión, el Instituto de Cooperación Iberoamericana (ICl) entregó 450 libros, haciendo referencia simbólica a la cantidad de años transcurridos desde aquella efeméride. Asimismo, se realizó una exposición de pintura sevillana, en la que destacaban obras de Velázquez y Zurbarán. También tuvo lugar la visita de editores y distribuidores de libros de España. Durante la segunda mitad de los años 80 , hubo una estrecha relación entre algunos escritores peruanos y el Gobierno español: en 1986, Mario Vargas Llosa recibió el premio Príncipe de Asturias. Además, el ICI realizó en 1987 un homenaje a Alfredo Bryce Echenique, y en 1987 se conmemoró el $50^{\circ}$ aniversario del fallecimiento de Cesar Vallejo, no solo en Perú, sino también en la ciudad de Madrid. 
Tras la llegada al poder de Alberto Fujimori en el Perú, en 1990, se iniciaron en Lima las operaciones del programa Patrimonio para el Desarrollo de la entonces llamada Agencia Española de Cooperación Internacional (AECI).

\section{La Cooperación Española a lo largo del tiempo}

En noviembre de 1940 el Gobierno español creó un organismo oficial, el Consejo de la Hispanidad' $(\mathrm{CH})$, con la finalidad de ejercer influencia política e ideológica en Hispanoamérica, de acuerdo con los propósitos del partido Falange Española Tradicionalista (FET). Eduardo Calleja acota, sobre las políticas exteriores de los primeros años del franquismo, lo siguiente:

La Delegación Nacional del Servicio Exterior de FET jugó un papel destacado en la formulación y ejecución de una política internacional más dogmática y agresiva, centrada en las aspiraciones de imperialismo cultural hacia lberoamérica, el control de las colonias españolas en el Nuevo Mundo, la vigilancia de los exiliados republicanos y la estrecha vinculación con los movimientos políticos afines de uno y otro lado del Atlántico. (Calleja, 1994, p. 207)

Este intento de control derivó en una serie de denuncias y terminó siendo un fracaso. Calleja menciona que la opinión internacional en esos años no dudó en identificar al falangismo con el imperialismo fascista o nacional socialista, lo cual devino en rechazo hacia España.

Tras el fin de la Segunda Guerra Mundial, la política exterior del régimen español cambió drásticamente, y también sus políticas de control destinadas a Hispanoamérica: desapareció el Consejo de la Hispanidad. Entonces Franco buscó apoyo en la Iglesia católica y, mediante la Ley del 31 de diciembre de 1945, se creó el Instituto de Cultura Hispánica (ICH) tomando como base la organización de los servicios del Ministerio de Asuntos Exteriores y con carácter de órgano asesor del Ministerio. El ICH fue producto del sector católico del gobierno de Franco, que se desvinculó totalmente del asedio político falangista, y dio inicio a una nueva etapa de ambiciones políticas que tenían como fin principal el beneficio en relación a asuntos exclusivamente culturales y espirituales (Navarro, 2011).

El principal objetivo para el cual fue creado el ICH se detalla en el artículo 13 de la ley que lo vio nacer: "mantener y estrechar los vínculos espirituales entre todos los pueblos que componen la comunidad cultural de la Hispanidad" (Rosa, 1947, p. 61). Es por este motivo que el Instituto movilizó cuanto elemento estaba a su alcance para fomentar el mutuo conocimiento entre los pueblos hispánicos e intensificar sus recíprocas relaciones culturales. Respecto a las políticas que regían el ICH, Antonio Cañellas resume lo siguiente:

El Instituto de Cultura Hispánica respondió al interés por retomar el diálogo con los países iberoamericanos desde una óptica cultural aparentemente desideologizada, pero que por su interpretación esencialista de la historia hispánica generaría una teología política propia, ligada a las pautas del tradicionalismo católico. Con ello se definiría el contenido y actividad del Instituto en todos los ámbitos posibles, para inaugurar -dentro del bloque occidental- una auténtica Comunidad Hispánica de Naciones, fundada en esos principios que aspiraba a liderar España en su objetivo por superar el bloqueo diplomático. (2014, p. 62)

El ICH comenzó a funcionar el 18 de abril de 1947, tras la aprobación de su reglamento, que especificaba los siguientes fines: el estudio, defensa y difusión de la cultura hispánica; el fomento del mutuo conocimiento entre los pueblos hispánicos y la inten- 


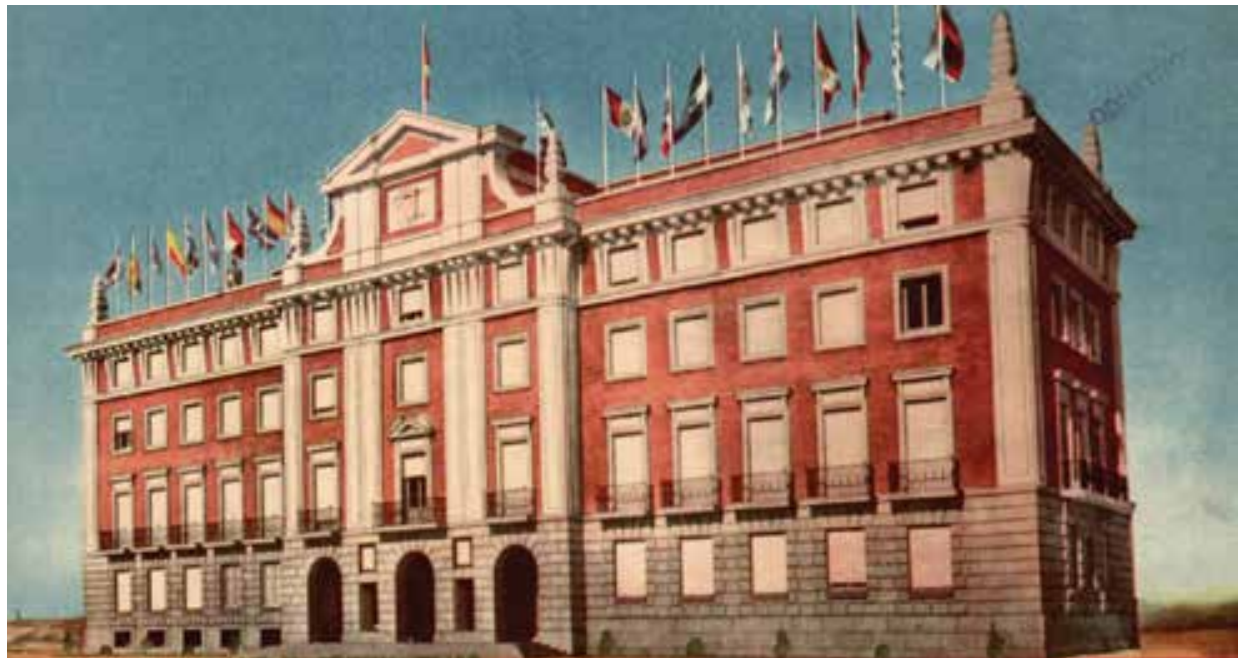

Figura 1. Colegio Mayor Hispanoamericano Nuestra Señora de Guadalupe. En El Instituto de Cultura Hispánica al servicio de Iberoamérica (p. 4), por Instituto de Cultura Hispánica, 1953.

sificación de su intercambio cultural; la ayuda y coordinación de todas las iniciativas públicas y privadas que conduzcan al logro de los fines anteriores; y el asesoramiento del Ministerio de Asuntos Exteriores en dichas materias (Navarro, 2001).

Para poder estimular la migración de estudiantes a España, el ICH adoptó una política de otorgamiento de becas. Ahora, si bien la dotación de becas data de mucho antes de la formación del Consejo de la Hispanidad (1920), fue recién en esta etapa que se priorizó dicho mecanismo, el cual alcanzó su máxima cifra de beneficiarios en 1963, con un total de 315 estudiantes becados (Navarro, 2011). Las becas consistían en estudios de especialización de dos años. Una vez llegados los becarios a España, el ICH se encargaba de guiarlos e incluso los ayudaba a resolver su alojamiento. Debido a esto se implantó el Colegio Mayor Hispanoamericano de Nuestra Señora de Guadalupe, un recinto propio del ICH, creado por Decreto de 17 de enero de 1947. Gracias a su ubicación en el interior de la ciudad universitaria de Madrid, el estudiante de intercambio era acogido en un ambiente confortable y cómodo, donde la convivencia con los estudiantes españoles fortalecía los lazos culturales (Rosa, 1947). La labor del ICH en beneficio de los estudiantes hispanoamericanos fue trascendental: el Departamento de Asistencia Universitaria del Instituto atendió en su momento a una media anual de 3,000 estudiantes (Instituto de Cultura Hispánica, 1953). Se les brindaba atención médica, y apoyo académico y económico (Figura 1).

En diciembre de 1955, España fue finalmente aceptada en las Naciones Unidas. El ICH jugó un papel importante en su incorporación, ya que fue el encargado de revertir la imagen de España en Hispanoamérica: encontró representatividad en Argentina, Bolivia, Brasil, Colombia, Costa Rica, Cuba, Chile, Ecuador, Honduras, México, Nicaragua, Panamá, Paraguay, Perú, Puerto Rico, República Dominicana y Uruguay.

El rey Juan Carlos I encargó al presidente del Gobierno, luego de la muerte del dictador el 3 de julio de 1976, el cese de las instituciones del franquismo. Tuvo lugar entonces otro cambio en la orientación de la política exterior española. El órgano esencial de la administración del Estado para la política iberoamericana, el ICH, atravesó una serie de cambios que alteraron su denominación y organización interna: mediante Real Decreto 2258/1977, del 27 de agosto, el ICH se convirtió en el Centro Iberoamericano de Cooperación (CIC), un organismo autónomo anexado al Ministerio de Asuntos Exteriores del gobierno español. Así, se dejó de lado el enfoque anterior del ICH para centrar- 
se en las relaciones culturales y espirituales como un puente para recuperar el vínculo con Iberoamérica. En esta nueva etapa se implementa el término cooperación como parte de una nueva política y se busca el desarrollo económico, comercial y financiero, así como la acción científica y cultural, o la colaboración tecnológica e industrial.

Dos años después, se llevó a cabo la segunda remodelación mediante Real Decreto 2411/1979, del 11 de octubre, mediante el cual el CIC pasó a llamarse Instituto de Cooperación Iberoamericano $(\mathrm{ICl})$. Esto implicó también una ampliación de sus funciones hacia el ámbito científico, tecnológico y económico, sin dejar de lado el aspecto cultural. Durante los primeros gobiernos socialistas se ejecutaron cambios institucionales: en 1985 se creó la Secretaría de Estado para la Cooperación Internacional y para Iberoamérica por Real Decreto 1485/1985, del 28 de agosto, en el seno del Ministerio de Asuntos Exteriores, y se puso bajo su dependencia a todos los centros y organismos destinados a estos círculos, entre ellos el ICl. Una nueva reestructuración de los organismos de cooperación se llevó a cabo, mediante Real Decreto 1527/1988, del 11 de noviembre, que significó la fusión de las entidades de cooperación, que entonces eran el Instituto Hispano-árabe y el ICl. Así se formó la Agencia Española de Cooperación Internacional $(\mathrm{AECl})$, organismo autónomo del Ministerio de Asuntos Exteriores y Cooperación. Posteriormente, mediante la Ley 23/1998, del 7 de julio, se configuró la $\mathrm{AECl}$ como el único órgano ejecutivo de la política española de cooperación internacional para el desarrollo. Así, se consagró como el principal órgano de gestión de la Cooperación Española, cuyo objetivo principal es el desarrollo humano sostenible y la lucha contra la pobreza. Es en ese momento que se pone en marcha, como una de sus directrices para lograr sus objetivos, el programa Patrimonio para el Desarrollo, el cual se implementó en el Perú en 1990.

En síntesis, el CH, creado en España durante el franquismo, tuvo como objetivo principal ejercer control político e ideológico en los países iberoamericanos antiguamente pertenecientes a la Corona de España, para así generar respaldo internacional al nuevo régimen. Durante esta etapa, que duró cinco años, prevaleció la dimensión cultural; se instauró el término hispanidad para englobar a un conjunto de naciones vinculadas culturalmente con España. El impacto del $\mathrm{CH}$ no fue el esperado, y más bien recibió denuncias por acoso e intromisión por parte de los nuevos gobiernos de América Latina, que vieron este asedio político como un claro intento de injerencia en su soberanía. Por esa razón se creó el ICH, un nuevo organismo mediante el cual se buscó -a través de la religión- crear los vínculos necesarios con los países de la antigua monarquía. También se empleó la estrategia de dotar a la población estudiantil de becas para estudiar en España, nuevo destino educativo después de la Segunda Gran Guerra. Durante 32 años fue la institución rectora del Gobierno español en cuanto a su política internacional. En esta etapa, el ICH se centró en los estudiantes, y priorizó el fortalecimiento de los vínculos, tendiendo puentes a partir de la historia y la religión en común. Una vez logrado el intercambio estudiantil, se intentaba conseguir, a través de la convivencia, la creación de otros lazos culturales. No hubo interacción institucional, de manera que no se trabajó en los países sede ningún tipo de apoyo que no fuese el de las becas.

Tras la muerte de Franco, se efectuó un cambio en el organismo de política internacional y, como se ha mencionado previamente, el ICH se convirtió en el $\mathrm{ClC}$, el cual tendría un periodo corto de dos años de vida. En este caso, por la brevedad, no existió un plan rector que lo diferenciase de su antecesor, y se siguieron abarcando las mismas dimensiones aunque con menor intensidad. Posteriormente, en 1979 el CIC se convirtió en el ICl, el cual básicamente seguiría los lineamientos del antiguo ICH. A pesar de ser el resultado de la fusión de instituciones, no existió mayor planeamiento sobre otras políticas durante sus nueve años de existencia. Se continuó otorgando becas de estudios con la finalidad del intercambio cultural, sin producir mayor relación entre instituciones con los países-sede. 


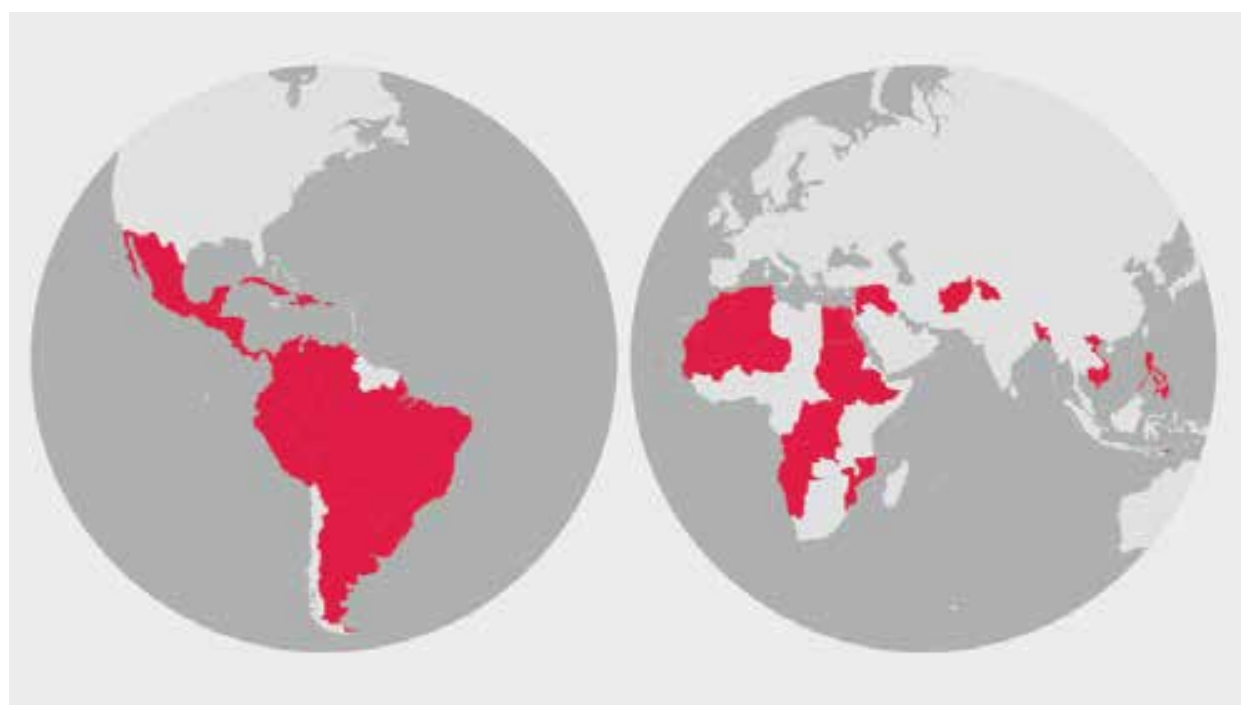

Figura 2. Prioridades geográficas de la Cooperación Española. En 25 años Cooperando con América Latina y el Caribe. Volumen II: Exposiciones (p. 10), por AECID, 2015a.

Finalmente, en 1988 se creó la $\mathrm{AECl}$, a partir de entonces el único agente del Gobierno central español en ese ámbito. Entonces se establecieron los lineamientos económicos e institucionales, y se trabajó con las personas más vulnerables. Para ello, se creó una nueva entidad capaz de brindarles formación en labores de restauración, para así poder insertarlas en el ámbito laboral. Actualmente la AECI brinda capacitación para restaurar, así como apoyo a las instituciones de los gobiernos de América Latina. En 2004, se convocó a elecciones en España, y entró al poder el Partido Socialista Obrero Español (PSOE). Esto influyó en la $\mathrm{AECl}$, que entonces pasó a llamarse Agencia Española de Cooperación Internacional para el Desarrollo (AECID).

\section{La Cooperación Española en América Latina y El Caribe}

La presencia de la Cooperación Española es casi total en América Latina, con excepción de Chile, que no es parte de su prioridad regional (Figura 2).

El programa Patrimonio para el Desarrollo trabaja en tres ámbitos: centros históricos, paisajes culturales y sitios arqueológicos. Teniendo en cuenta estos escenarios, la Cooperación Española ha desarrollado en el Perú siete proyectos en diferentes regiones: Lima, Arequipa (en el Centro Histórico y Valle del Colca), Cusco, Huamanga, Lambayeque y Yucay. Estas representan el $10 \%$ del total de ciudades con presencia de Cooperación Española en América Latina y el Caribe (AECID, 2015a). Sin embargo, la cantidad de sitios intervenidos no es necesariamente directamente proporcional a la inversión realizada. Durante los 25 años de presencia de la Cooperación Española en América Latina, el Caribe y África, el Perú ha sido el principal receptor de inversión, seguido por Bolivia, los territorios palestinos y Guatemala (Figura 3).

Un acierto de la Cooperación Española ha sido la creación de las Escuelas Taller (ET), destinadas a trabajar con la población vulnerable capacitándola e insertándola en el ámbito laboral, y haciéndola partícipe del proceso de recuperación del patrimonio. En una de las visiones que se plantean por los 25 años de cooperación, la AECID menciona al respecto que "durante el periodo comprendido entre 1991 y 2010 se han promovido 249 proyectos de Escuelas Taller en el exterior, en 67 ciudades pertenecientes a 24 países en los que se han formado 27,000 alumnos y alumnas" (AECID, 2015a, p. 66) (Figura 4). 


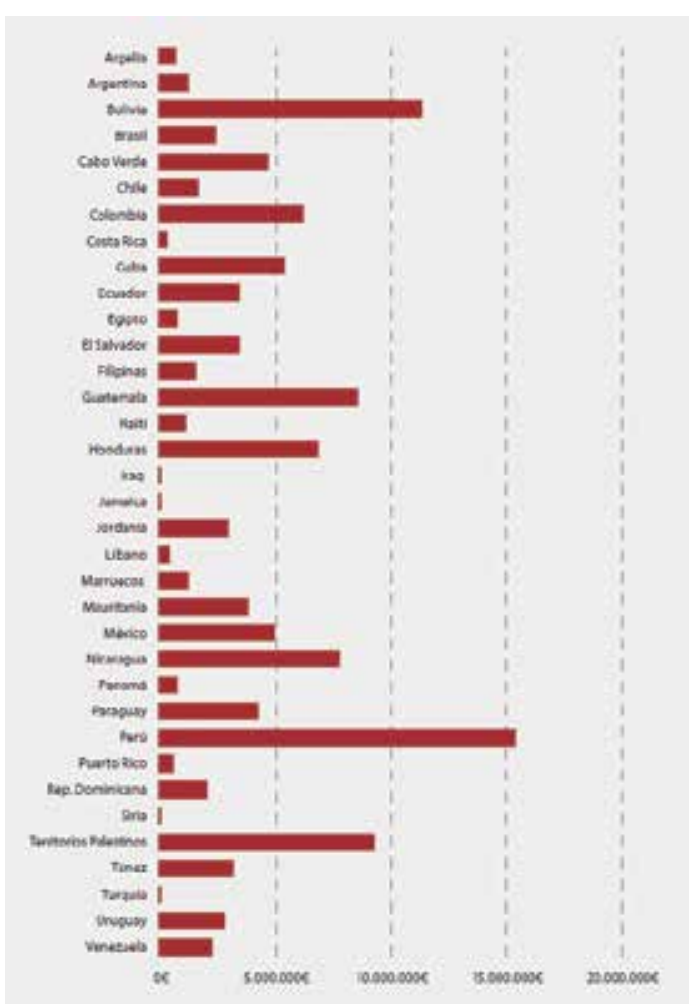

Figura 3. Inversión en proyectos de puesta en valor del patrimonio en países que son prioridad para la Cooperación Española. En 25 años Cooperando con América Latina yel Caribe. Volumen Il: Exposiciones (p. 26), por AECID, 2015a.

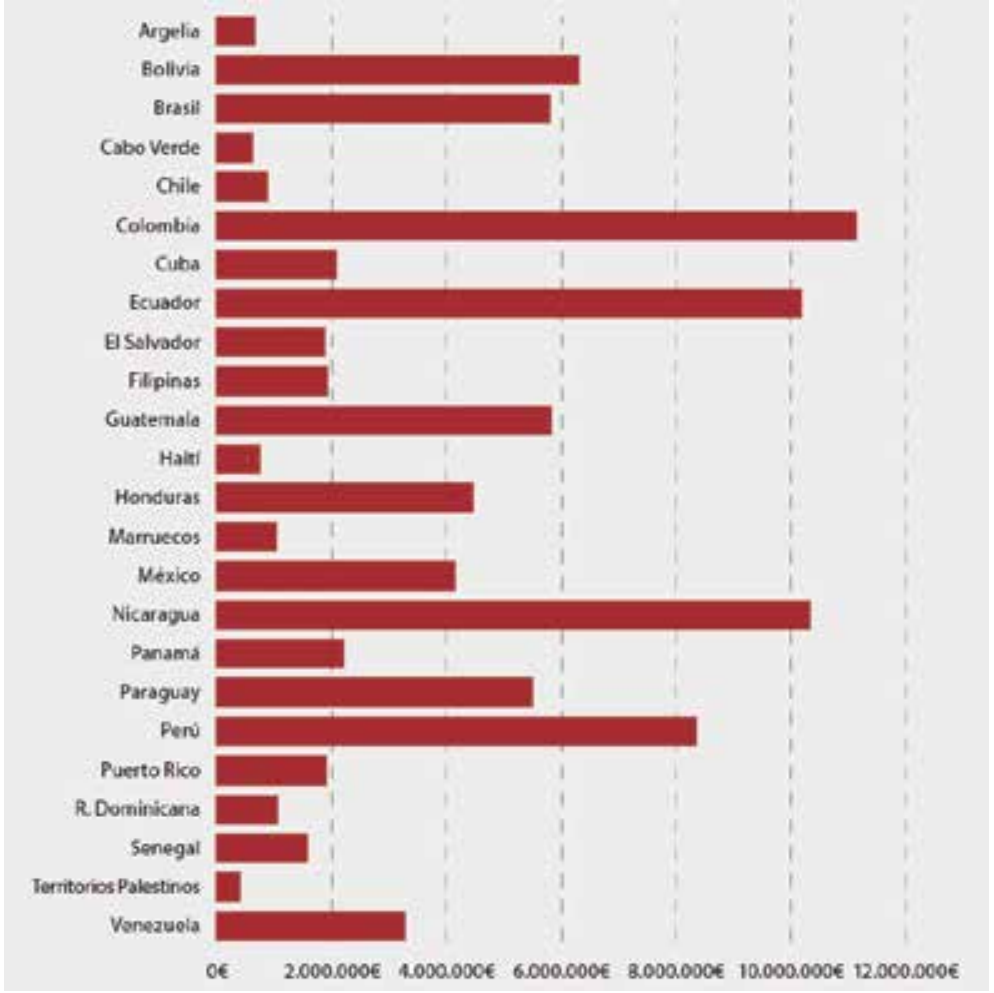

Figura 4. Inversión en Escuelas Taller en países que son prioridad para la Cooperación Española. En 25 años Cooperando con América Latina y el Caribe. Volumen II: Exposiciones (p. 69), por AECID, 2015a.

De las 62 ET existentes en América Latina y el Caribe, cuatro están ubicadas en Perú: ET de Lima, ET de Cusco, ET de Arequipa y ET del Colca, las cuales representan el $6.5 \%$ de todas las presentes en la región.

\section{La Cooperación Española en el Perú}

La Cooperación Española inició sus labores en el Perú en las ciudades de Cusco y Lima. En cuanto a Cusco, existe un convenio previo de cooperación que propició la acometida, en 1988, de las obras de emergencia en la Iglesia de la Compañía de Jesús. Los trabajos realizados en 1990 fueron parte del programa Patrimonio para el Desarrollo. El otro foco de trabajo es Lima, por ser capital del Perú, ciudad que tomó la iniciativa de solicitar su inscripción en la lista de Patrimonio Mundial de la Unesco. Las labores en la capital se iniciaron con la fundación de la Escuela Taller en la Quinta de Presa, y luego se intervino la iglesia de San Francisco, específicamente la sacristía. Después de un tiempo de brindar apoyo en estas dos ciudades, se realizaron trabajos en otras provincias del país. Muchos años después, se sumaron las ET de Arequipa, el Centro Histórico y el Colca.

Los trabajos que la Cooperación Española ha realizado en el Perú durante más de 20 años pueden clasificarse en cuatro categorías:

1. Intervención directa: Conservación, restauración, actividades de emergencia o consolidación de edificios en riesgo.

2. Apoyo institucional: Apoyo en planes maestros para centros históricos, gestión patrimonial y sensibilización de la población. 


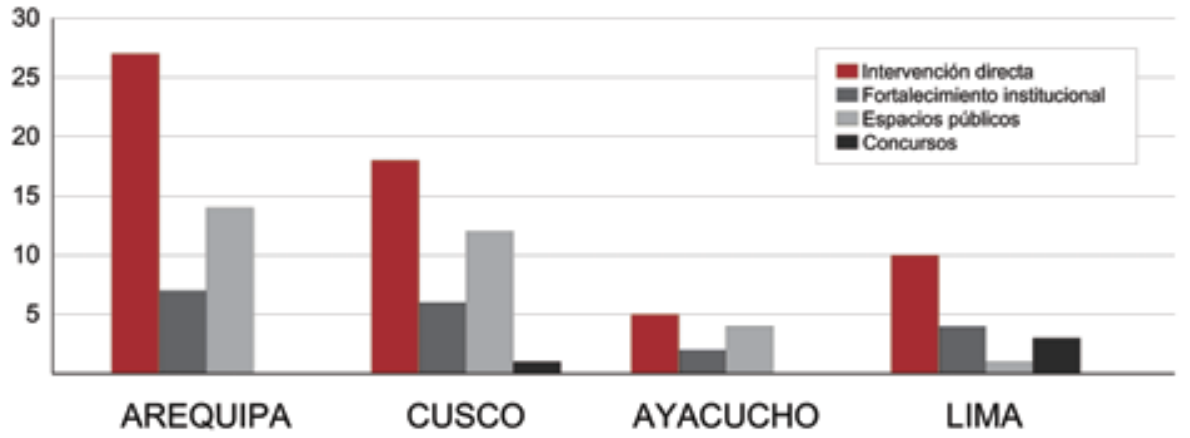

Figura 5. Intervenciones llevadas a cabo en las principales ciudades del Perú. Elaboración propia, 2016.

3. Espacios públicos: Regeneración urbana, y remodelación de jirones, calles y plazuelas.

4. Concursos de ideas: Convocatorias para mejorar espacios públicos.

Del total de intervenciones realizadas, el $58 \%$ (80) fueron de intervención directa; el 23 $\%$ (31), en espacios públicos; el $16 \%$ (22), de apoyo institucional; y el $3 \%$ restante (4) corresponden a concursos de ideas.

En cuanto a su distribución en el territorio, las intervenciones realizadas en la capital representan el $13 \%$ de los trabajos realizados a nivel nacional. En cuanto las cuatro categorías previamente mencionadas, las intervenciones realizadas en Lima se distribuyen de la siguiente manera:

1. La intervención directa en Lima representa el 12\% del total realizado en Perú

2. El apoyo institucional en Lima representa el $18 \%$ del total realizado en Perú

3. Los espacios públicos en Lima representan el 3\% del total realizado en Perú

4. Los concursos de ideas en Lima representan el 75\% del total realizado en Perú (Tabla 1 y Figura 5)

\section{La Cooperación Española en Lima}

En la ciudad de Lima, la Cooperación Española tiene predisposición a trabajar en el Centro Histórico. De las 18 intervenciones en patrimonio inmueble registradas, 13 se realizaron en esta zona, y solo cinco fuera de su perímetro. Estas últimas intervenciones son las siguientes:

- La rehabilitación de la sede del Centro Cultural de España, ubicada en Santa Beatriz, en el Cercado de Lima (1995-1996)

- La conservación del edificio de la residencia del embajador de España en el Perú, ubicado en el distrito de Barranco (1997-2010)

- La restauración del mirador de la avenida Sáenz Peña, ubicado también en el distrito de Barranco (1999)

- El estudio estratigráfico y la elaboración de la cartilla de colores de un monumento situado en el distrito de Ancón (1999)

- La rehabilitación de la sede de la Oficina Técnica de Cooperación de la AECID, ubicada en el distrito de San Isidro (2005-2008). 
devenir Vol. 5, N¹0, JULIO - DICIEMBRE 2018, Pp. 109-134 - EstudIOS I ISSN 2312-7562 I E-ISSN 2616-4949 UNIVERSIDAD NACIONAL DE INGENIERÍA, LIMA

DOI: https://doi.org/10.21754/devenir.v5i10.601

Tabla 1. Cronología de intervenciones realizadas en el Perú. Elaboración propia, 2016.

\begin{tabular}{|c|c|c|c|c|}
\hline & & & \multirow{2}{*}{ 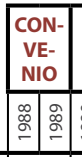 } & PROGRAMA: PATRIMONIO PARA EL DESARROLLO \\
\hline & & & & 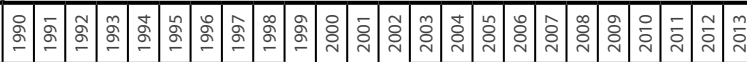 \\
\hline & & Plan Maestro & & \\
\hline & & Escuela Taller Arequipa & & \\
\hline & & Conjunto de la Compañía de Jesús & & \\
\hline & & Conjunto de San Francisco & & \\
\hline & & Convento de la Recoleta & & \\
\hline & & Centro Cultural El Ateneo-Casa de la Juventud & & \\
\hline & & Palacio Municipal de la Cultura & & \\
\hline & & Monasterio de Santa Catalina & & \\
\hline & & Basilica Catedral & & \\
\hline & & Casa del corregidor Maldonado & & \\
\hline & $\frac{0}{2}$ & Capilla de los Sagrados Corazones de Jesús & & \\
\hline & 뿠 & Casa Meneses & & \\
\hline & 邖 & Casa-Refugio Niña María & & \\
\hline & o & Casa Cornejo & & \\
\hline & $\bar{\sigma}$ & Casona Hipólito Sánchez Trujillo & & \\
\hline & $\stackrel{n}{=}$ & Barrio de San Antonio Abad & & \\
\hline & $\circ$ & Barrio de San Lázaro & & \\
\hline & $\sum_{\mathrm{u}}$ & Barrio del Solar & & \\
\hline & & Calle Mercaderes y plaza 155 de Agosto & & \\
\hline & & Eje La Merced - Álvarez Thomas & & \\
\hline & & Plaza San Francisco & & \\
\hline & & Calle Zela & & \\
\hline & & Pasaje 28 de Julio & & \\
\hline 5 & & Plazoleta Colón & & \\
\hline$\stackrel{\breve{\varkappa}}{\breve{x}}$ & & Alameda Chávez Velando & & \\
\hline & & Calle Puente Bolognesi & & \\
\hline & & Parque Miguel Cervantes & & \\
\hline & & Plaza de la Civilidad & & \\
\hline & & Sede del proyecto & & \\
\hline & & Oficinas locales de planeamiento & & \\
\hline & & Plan de Acondicionamiento Territorial & & \\
\hline & & Reserva Nacional Salinas y Agua Blanca & & \\
\hline & & Área monumental de Coporaque & & \\
\hline & & Templo de la Purísima Concepción de Lari & & \\
\hline & & Templo de Santa Ana de Maca & & \\
\hline & & Templo Nuestra Señora de la Asunción de Chivay & & \\
\hline & 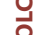 & Templo San Juan Bautista de Ichupampa & & \\
\hline & تِ & Templo Inmaculada Concepción de Yanque & & \\
\hline & $\overline{\mathrm{O}}$ & Templo Santiago Apóstol de Madrigal & & \\
\hline & 己े & Templo San Pedro Alcántara de Cabanaconde & & \\
\hline & & Templo San Sebastián de Pinchollo & & \\
\hline & & Templo de los Santos Reyes Magos de Achoma & & \\
\hline & & Templo de San Lorenzo de Huambo & & \\
\hline & & Templo de San Lorenzo de Tapay & & \\
\hline & & Templo Santiago Apóstol de Canocota & & \\
\hline & & Templo San Juan Bautista de Sibayo & & \\
\hline & & Cruz catequística de Tuti & & \\
\hline & & Escuela Taller Colca & & \\
\hline
\end{tabular}


Tabla 1. Cronología de intervenciones realizadas en el Perú. Elaboración propia, 2016.

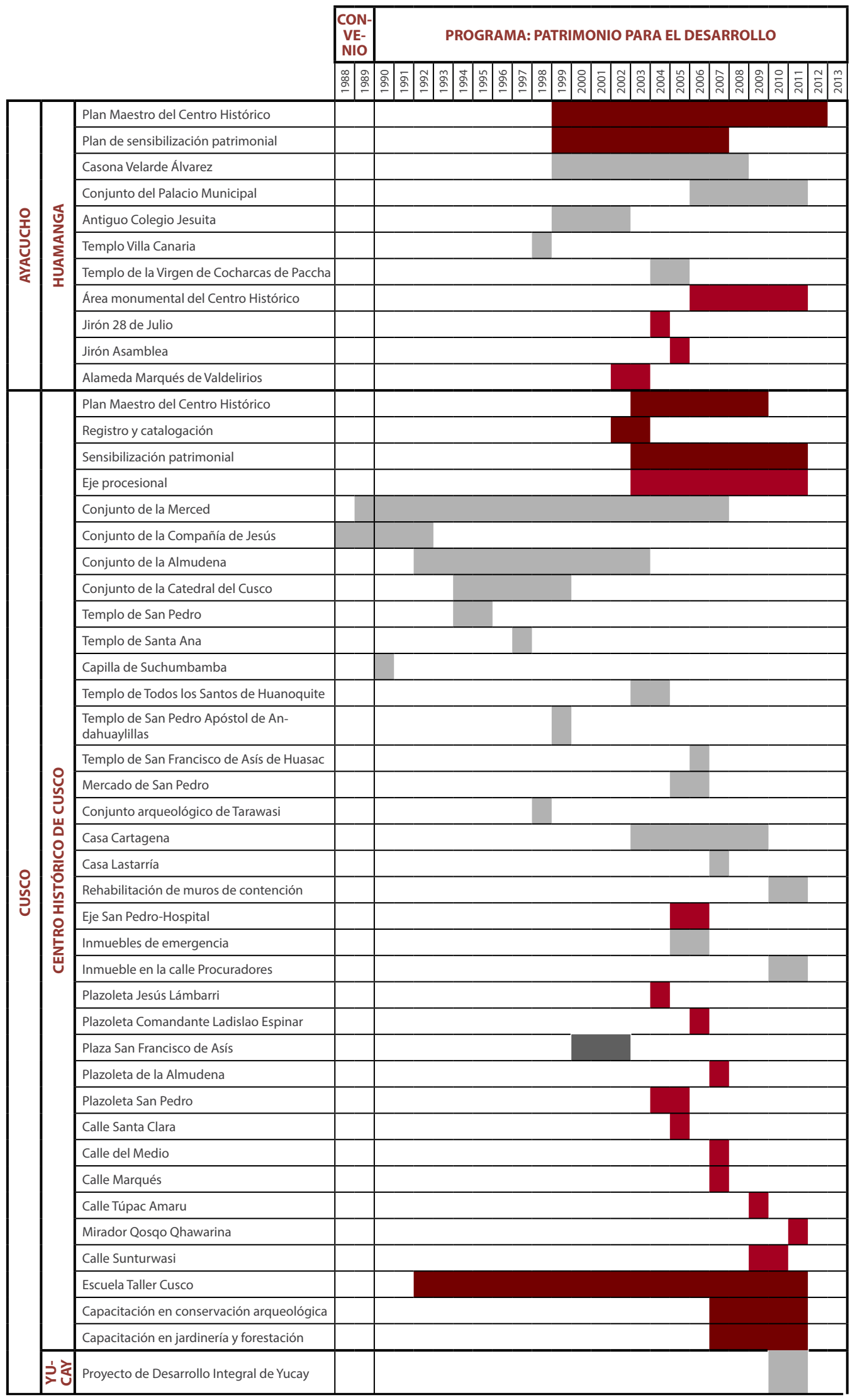


devenir Vol. 5, N¹0, JULIO-DICIEMBRE 2018, PP. 109-134 - EstUdIOS I ISSN 2312-7562 I E-ISSN 2616-4949

UNIVERSIDAD NACIONAL DE INGENIERÍA, LIMA

DOI: https://doi.org/10.21754/devenir.v5i10.601

Tabla 1. Cronología de intervenciones realizadas en el Perú. Elaboración propia, 2016.

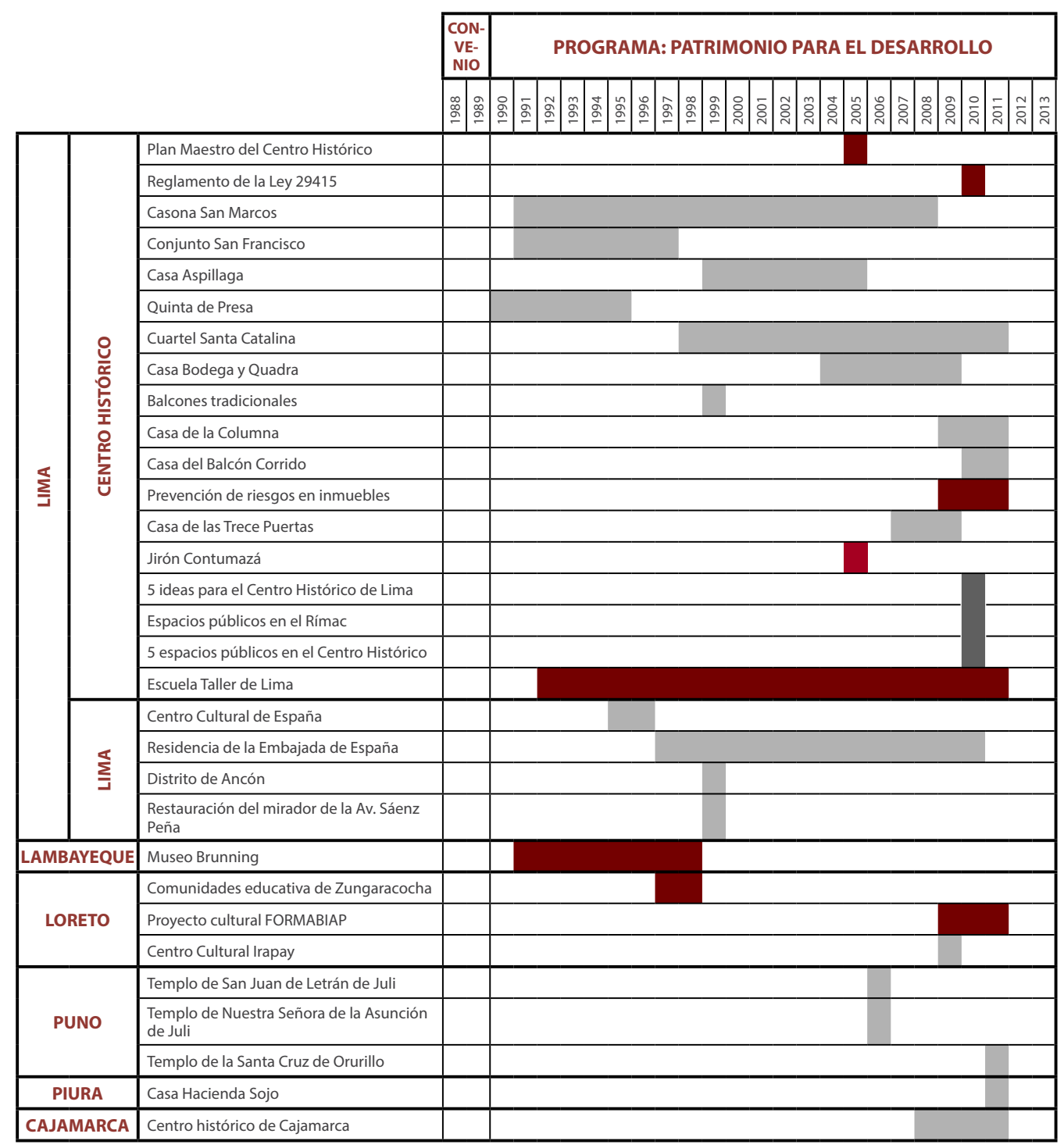

En Lima, estas intervenciones fuera del Centro Histórico representan el $28 \%$ del total de esta categoría. Sin embargo, existe también cierta territorialidad en el interior del mismo Centro Histórico, pues el mayor número de actuaciones se concentra dentro del área inscrita como Patrimonio Cultural de la Humanidad por la Unesco. Las operaciones directas realizadas fuera de dicha zona son solo dos: la Quinta de Presa, en el distrito del Rímac (1990-1995), y el cuartel de Santa Catalina, en Barrios Altos (19982011). Estas dos últimas intervenciones en el interior del Centro Histórico, pero fuera del área inscrita como Patrimonio Cultural de la Humanidad, representan el $15.5 \%$ del total efectuado en el área (Figura 6).

\section{Casona de San Marcos}

Fundada en 1605 como el Noviciado Jesuita de San Antonio Abad, la Casona de San Marcos se convirtió en 1767, tras la expulsión de dicha orden del Virreinato del Perú, en la sede del Real Convictorio de San Carlos, que agrupó a los tres colegios reales de 


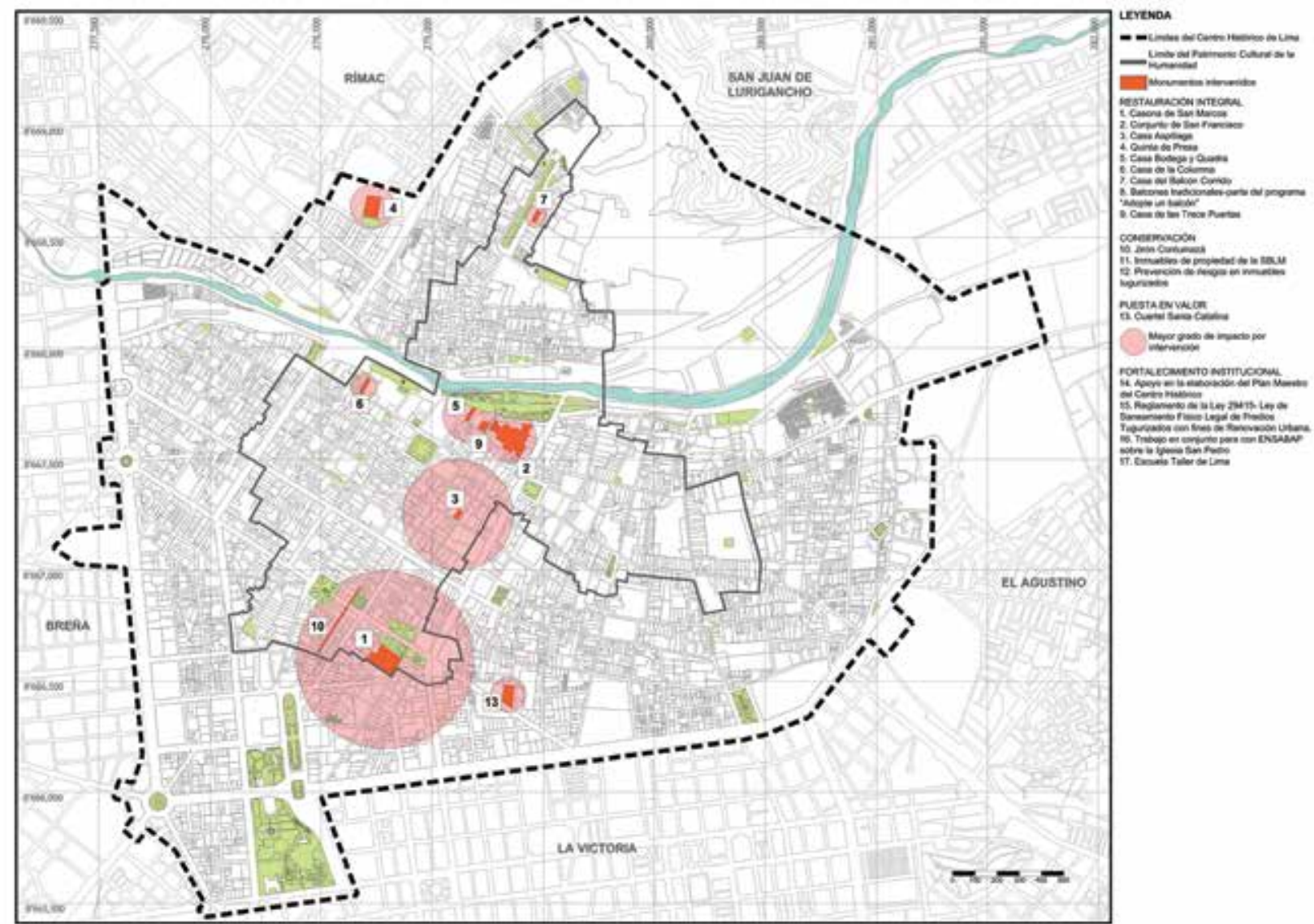

Lima. En 1821, ya proclamada la independencia del Perú, se convirtió en el Colegio de San Carlos, y en 1867 pasó a ser la casa de estudios de la Universidad Nacional Mayor de San Marcos (UNMSM), que fue desplazada del antiguo local que compartía con el Congreso de la República. Tras el terremoto de 1966, la UNMSM se trasladó a la Ciudad Universitaria, y la casona fue cedida a instituciones de extensión cultural (Burneo, 2013). Gran parte de sus ambientes quedaron clausurados o en ruina, mientras que aquellos menos deteriorados fueron ocupados por dependencias culturales y administrativas, así como por los depósitos de los museos. El estado de ruina del antiguo edificio fue considerado prácticamente irreversible, y surgieron propuestas para su demolición.

Posteriormente, en 1989, la UNMSM, la AECI y el entonces Instituto Nacional de Cultura (hoy Ministerio de Cultura) suscribieron el convenio Perú-España para restaurar este notable inmueble histórico, y adecuarlo a su nuevo uso integral como espacio dedicado a la investigación y creación artística.

En cuanto a su situación legal, el bien inmueble fue declarado Monumento mediante Resolución Suprema № 2900 en 1972, y se encuentra registrado en el Ministerio de Cultura con el nombre "Universidad Nacional Mayor de San Marcos originalmente sede del Noviciado Jesuita de San Antonio Abad y luego del Real Colegio de San Carlos" (Ministerio de Cultura, 2018, p. 19) (Figura 7).

Antes de iniciar el proceso de restauración, se llevó a cabo un análisis de la casona, realizado entre noviembre y diciembre de 1967 por A. Frischlander, para determinar los
Figura 6. Ubicación de las intervenciones directas realizadas por la Cooperación Española en el Centro Histórico de Lima. Elaboración propia, 2016. 


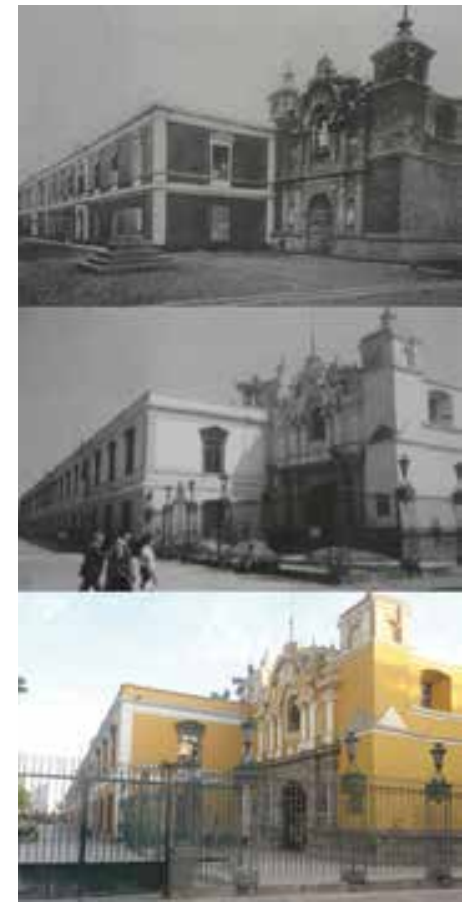

Figura 7. Iglesia de San Carlos con la portada de la Casona en 1890, 1995 y 2015. En Lima: Ayer y Hoy (p. 55), por K.W. Heinz, 1997. Fototeca personal de Jarim Melgar, 2015.

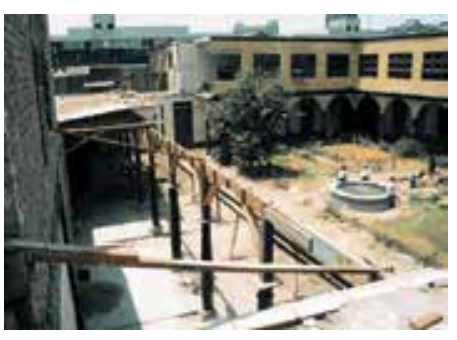

Figura 9. Retiro de elementos del Patio de los Jazmines. En Proyectos Perú 1990-2011 (p. 442), por AECID, 2012.
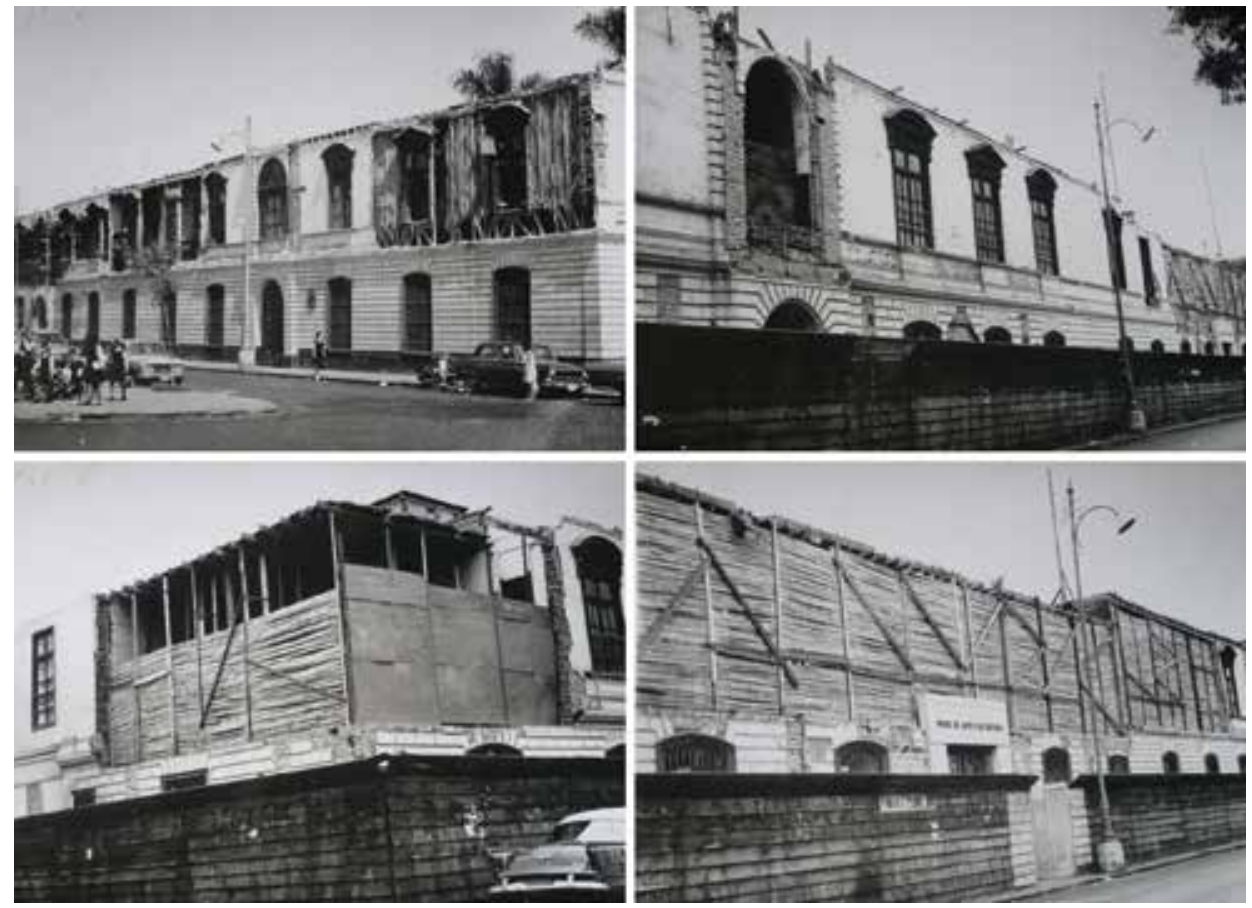

Figura 8. Estado de la Casona de San Marcos antes de su recuperación. Recuperado de http://www. limalaunica.pe/2018/03/casona-de-san-marcos-patrimonio-en.html

pasos a seguir para su posterior restauración. En el levantamiento publicado en 1968, se detalló la ocupación parcial de dos de los patios. El Patio de los Chicos, ubicado en la zona noroeste, presentaba una deformación en su planta cuadrangular, producto de las ampliaciones de los establecimientos. En cuanto al segundo, el Patio de los Jazmines, se planteó una disminución de su área, pero manteniendo su forma regular (ver Figuras 8 y 9 ).

La restauración del inmueble se inició en 1991, y por su magnitud la intervención se llevó a cabo por sectores. Una primera entrega de resultados se realizó tres años después de iniciados los trabajos de recuperación, y el resto de la cronología es la siguiente:

- Salón General: Entregado a la UNMSM en 1994

- Patio de Jazmines: Entregado en 1996

- Salón de Grados: Entregado en 1998

- Antigua Huerta: Entregada en 1999

- Patio de chicos: Entregado en 1999

- Patio de Letras: Entregado en 2003

- Patio de Ciencias: Entregado en 2005

- Patio Principal: Entregado en 2007

- Sector Cotabambas - antiguo Patio de Capistas: Entregado en 2011 (AECID, 2012) 


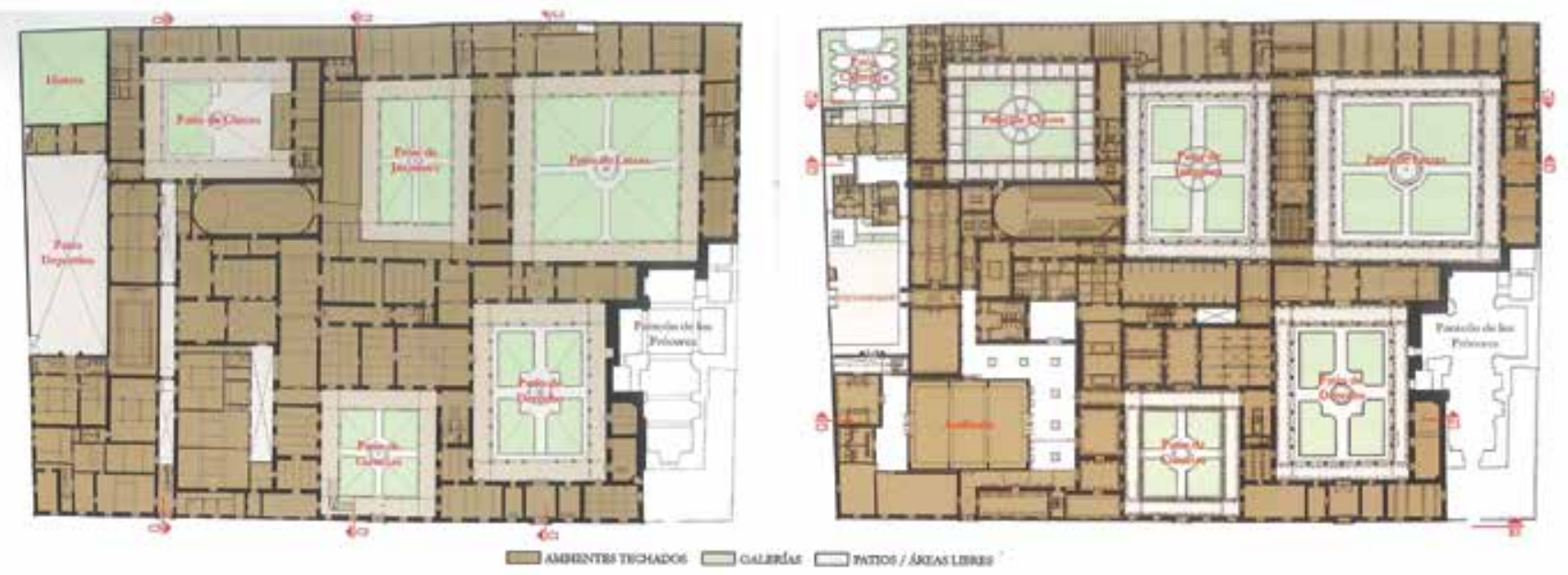

Figura 10. Planos comparativos del primer nivel, 1990-2012. En Orígenes y Evolución del Conjunto Arquitectónico de la Casona de San Marcos (pp. 64 y 112), por R. Burneo, 2013

Como menciona Martín Fabbri (2016), la lógica que acompañó la intervención fue ocuparse, primero, de los lugares más apartados del patio central, como una especie de ensayo que serviría como base para luego poder intervenir, ya con experiencia concreta, en las zonas de mayor valor histórico. La Escuela Taller de Lima acompañó el proceso de recuperación, pero su colaboración fue mínima, ya que se requirió de personal con mayor experiencia para los trabajos de restauración.

Sobre su adecuación al nuevo uso cultural, Pamela Bonilla afirma lo siguiente:

Un concepto importante aplicado en la Casona de San Marcos es el enaltecimiento de su vocación cultural mediante la inclusión de elementos didácticos. Además, el edificio tiene un amplio carácter social, lo que asegura su supervivencia a lo largo del tiempo. (2015, p. 51)

El Arq. Martin Fabbri (2016) señala como un logro de la UNMSM el haber tomado el reto de recuperar su casona y ponerla en valor. En una época en que se vivía una crisis nacional y donde nadie pensaba en invertir en patrimonio, la Universidad Nacional apostó por su permanencia en el Centro Histórico de Lima (ver Figura 10).

\section{Escuela Taller de Lima}

Las ET son organismos creados por la Cooperación Española, que pertenecen actualmente al marco de su programa Patrimonio para el Desarrollo, que oficialmente las define como"centros de trabajo y formación en los que jóvenes desempleados reciben formación técnica ocupacional en alternancia con la práctica profesional (en obra real, para rescate del patrimonio)" (AECID, 2007, p. 2). La ET de Lima se creó en 1985, gracias a la cofinanciación del Fondo Social Europeo. La formación que ofrecían consistía en una formación técnica de dos años de duración en oficios tradicionales, como albañilería y carpintería. Asimismo, se capacitaba respecto de autoempleo, PyMEs y prevención de riesgos laborales (ver Figura 11).

La ET inaugurada en Lima inició actividades en 1992, gracias al convenio firmado entre la AECl y el entonces INC. En sus inicios estuvo ubicada en la Quinta de Presa, y en 1998 fue reubicada en el antiguo Cuartel de Santa Catalina. Desde entonces la escuela ha generado diversos convenios: 


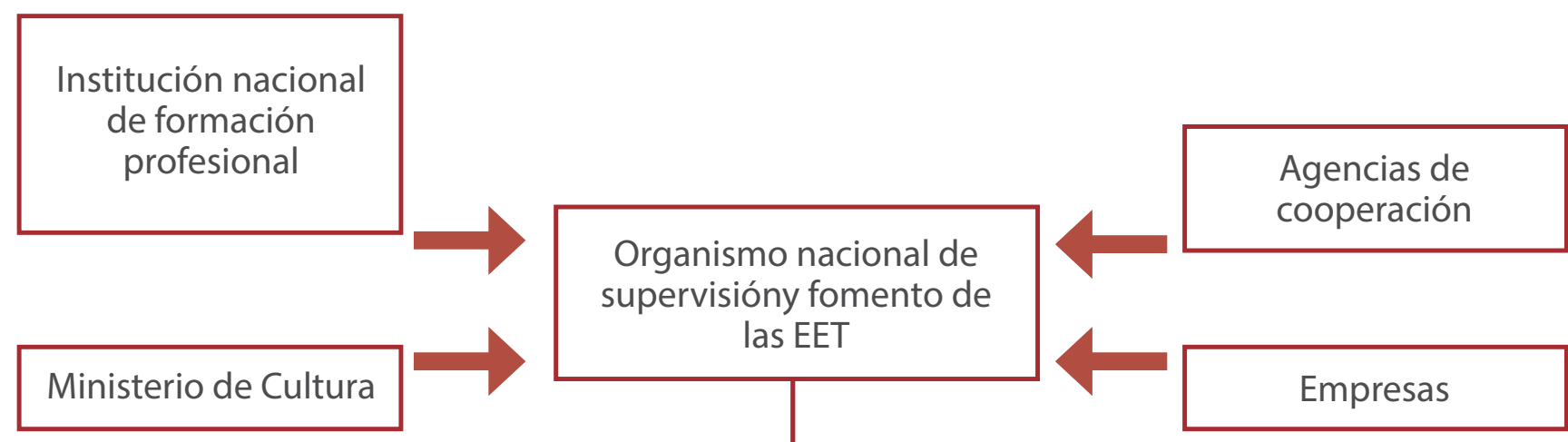

Figura 11. Organigrama de la Escuela Taller. En Las Escuelas Taller en su Laberinto: Nuevos Enfoques y Desafíos ( $\mathrm{p}$. 6), por AECID, 2007
- Convenio Marco, suscrito por el INC y la AECID

- Convenios 2004, 2005 y 2006, suscritos por la Municipalidad Metropolitana de Lima con la Provincial de Cusco y la AECID

- Protocolos anuales suscritos por el INC y la AECID

- Resolución directoral del INC N² 211, del 20 de junio de 1995, que reconoce y autoriza el funcionamiento de la Escuela Superior de Restauración Escuela Taller de Lima y le permite ofrecer estudios conducentes a títulos en cada una de las especialidades impartidas

- Resolución jefatural del INC № 850, del 13 de noviembre de 1992, que instituye la Escuela Taller de Lima como un programa especial, con autonomía técnica especial, económica y administrativa

- Ley No 28296, Ley General del Patrimonio Cultural de la Nación (21-julio-2004)

La formación ofrecida en la ET se basa en tres pilares fundamentales: la teórica en aula, la teórico-práctica en talleres y la práctica en obra. Esta última refiere al trabajo en campo de recuperación de ciudades. En el caso de la ET de Lima, los porcentajes que definen la formación son: $20 \%$ de formación teórica, 30 \% en talleres y, la mitad, $50 \%$, prácticas en obra (Larrea Tovar, 2015) (ver Figura 12). 


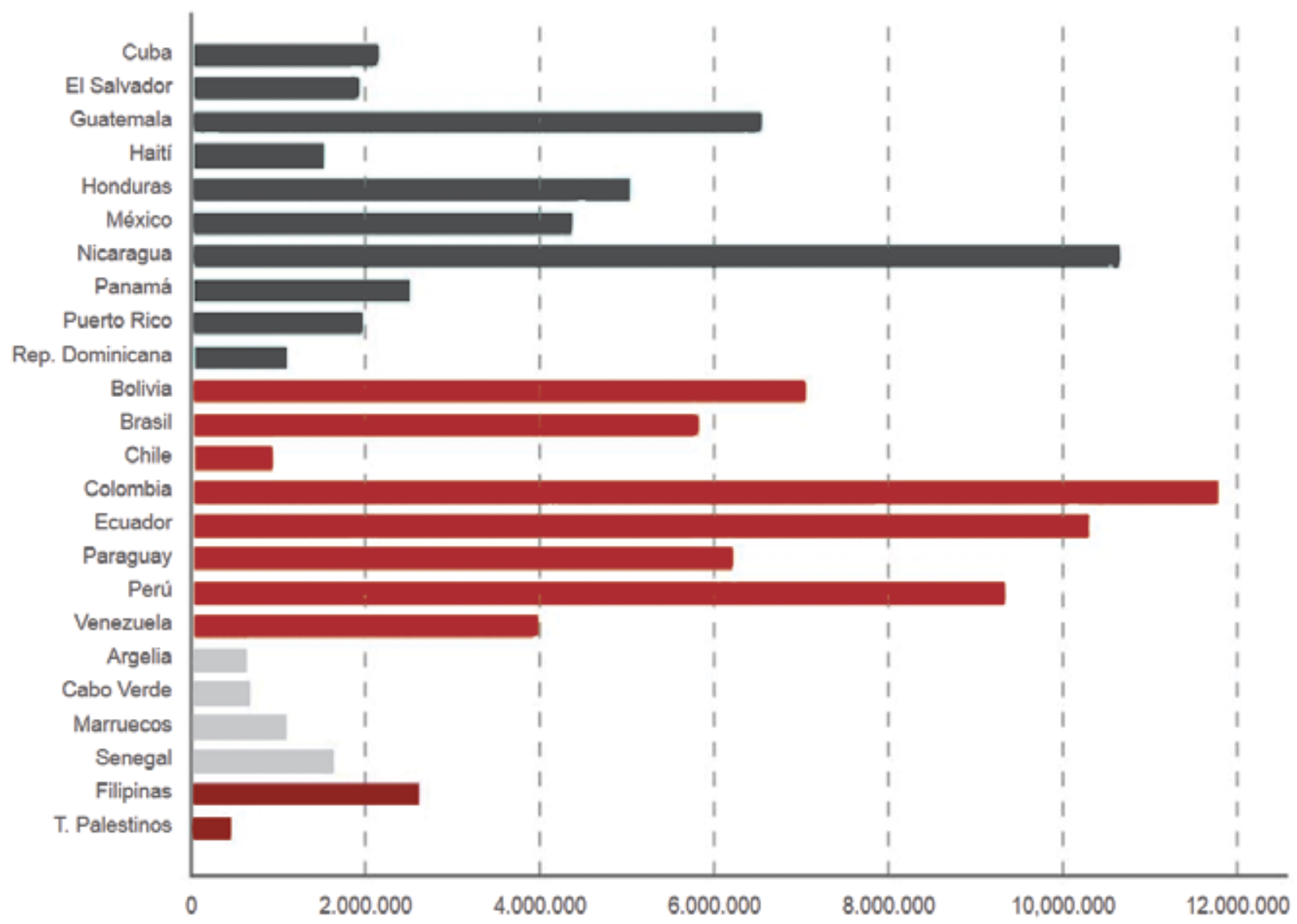

En la ET de Lima se enseñó cinco cursos base: albañilería, cantería, herrería y forja, carpintería y jardinería. En promedio, cada taller estaba conformado por 10 a 12 alumnos, como sostiene la arquitecta Mirna Soto Medina (comunicación personal, 21 de noviembre de 2016), exdirectora de la ET, cada grupo de alumnos contaba con un respectivo tutor que guiaba las labores. Se contaba, en total, con un promedio de 50 alumnos por periodo. Además del impacto social mencionado por la Arq. Mirna Soto, es necesario indicar que la ET, en el medio laboral, fue la primera en albergar capacitaciones sobre trabajos de restauración en Lima. En el caso de la ET de Lima, se buscó lograr la autogestión del centro y elevarlo a un mayor nivel académico. Al respecto, Soto Medina afirma lo siguiente:

Faltó ese enfoque gerencial, ya debían haber pasado a otro nivel. Por ejemplo, nunca se llegó a formalizar como una escuela técnica que otorgara títulos a nombre de la Nación. Entonces se entregaban certificados que no tenían el respaldo del Estado peruano. Ese fue un trabajo que lo iniciamos, porque yo fui encargada de rehacer los sílabos, las currículas de todos los cursos, enlazando los unos con los otros, para poder presentarlos al Ministerio de Educación y que nos permitiera el reconocimiento oficial. Se armó todo ese trabajo, pero finalmente no se concretó. El Estado pide una serie de requisitos. Todas las currículas estaban ya listas. Solo había que hacer la gestión, que lamentablemente no se hizo. En ese momento, yo me retiro de la Escuela Taller. (Comunicación personal, 21 de noviembre de 2016)

Otra deficiencia de la ET de Lima, si bien estaba destinada a trabajar con grupos sociales vulnerables, fue el hecho de no trabajar únicamente con la población del Centro Histórico. Se lanzaron convocatorias orientadas a personas de diversos distritos, cuya capacita-
Figura 12. Inversión de la cooperación para Escuelas Taller. En Programa de Escuelas Taller de la Cooperación Española: Aprender Haciendo (p. 27), por AECID, 2015b 


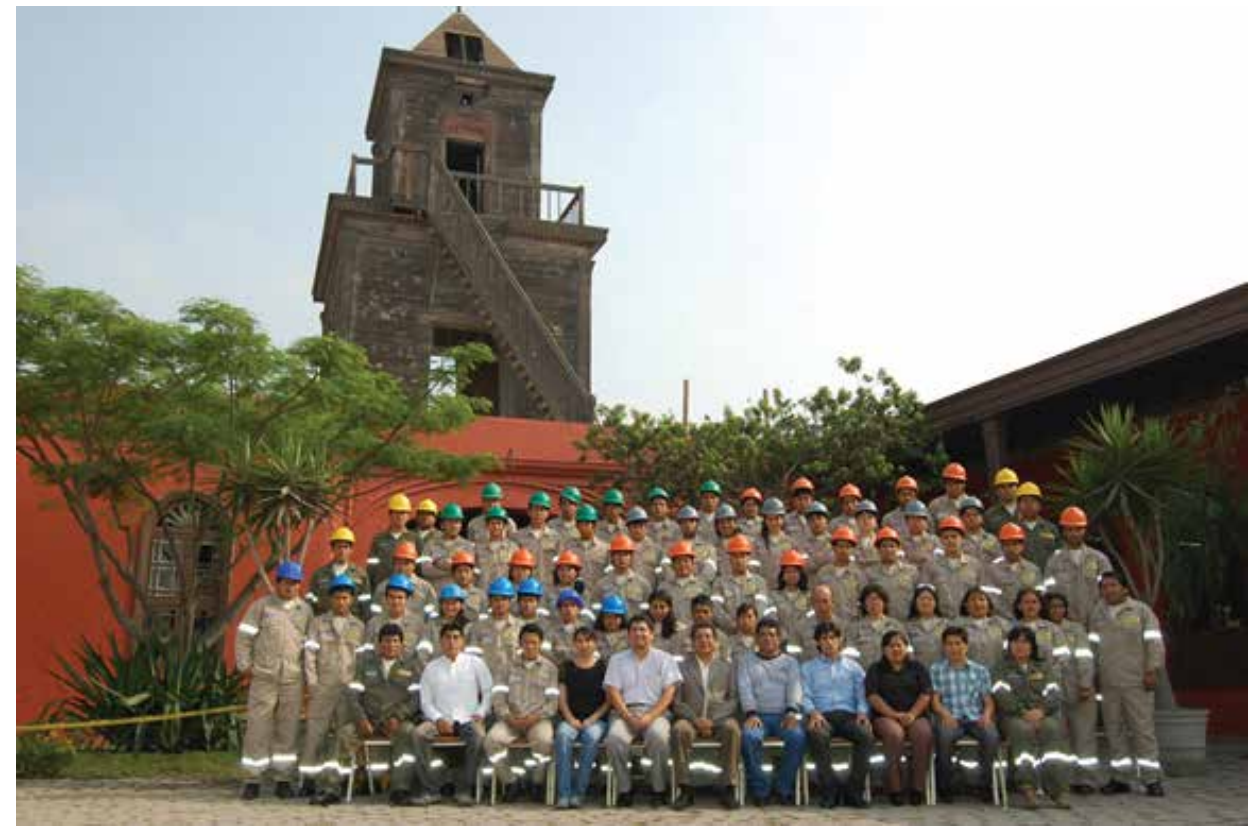

Figura 13. Promoción de estudiantes de la ET de Lima, 2011. Archivo personal de J. Larrea.

ción alcanzó cierto desarrollo; no obstante, el alcance pudo ser mayor si se hubiese focalizado la capacitación a personas naturales del centro. Según la Arq. Patricia Días Velarde,

La Escuela Taller ha tenido definitivamente un impacto social; sin embargo, lo que yo reclamaba era que esta Escuela Taller -al hacerse dentro del Centro Histórico de Lima- debió orientarse más a la población del centro. Debían haber promovido que participaran jóvenes que vivían allí, porque eso hubiera permitido que ellos, dentro de sus viviendas, pudieran replicar su experiencia de la Escuela Taller. (Comunicación personal, 28 de noviembre de 2016)

La experiencia de la ET de Lima no obtuvo el alcance deseado, debido a que el Estado peruano no respaldó la labor de la capacitación que allí se llevaba a cabo (Figura 13).

\section{Concursos de ideas}

Los concursos de intervenciones en espacios públicos son otra forma en que la Cooperación Española ha intervenido en el Centro Histórico. En esta modalidad de acción, apuesta por el espacio público como ente catalizador de su medio. Así, se ha trabajado en los ejes del Jirón Ancash y en cinco plazuelas; $y$, en el Rímac, en la Alameda de los Bobos-Descalzos y el Paseo de Aguas, junto a la Plazuela Quinta de Presa (ver Figuras 14 y 15).

Con estas actuaciones, la Cooperación no plantea otorgar un inmueble recuperado a la comunidad, sino que, a través de la valoración del espacio urbano monumental, se propicie el rescate de su entorno inmediato. Para lograr este cometido, se ejecutaron estos concursos de ideas, en conjunto con otras instituciones y con los municipios que tienen legislación sobre estos ambientes designados. Para ello, se llevaron a cabo convocatorias y la recolección de propuestas. En esta etapa se realizó un mayor hincapié en la difusión de resultados, pues la postura de la Cooperación era dar a conocer a la ciudadanía la revitalización de estos espacios públicos. En el caso del concurso en el Rímac, uno de los compromisos adquiridos por el municipio fue trabajar con los participantes de la propuesta ganadora la ejecución de esta. Lamentablemente, dicho compromiso no pudo concretarse y la remodelación de la Plazuela de Presa que se presentó en 2014 distó mucho de la propuesta ganadora del concurso (Figura 16). 


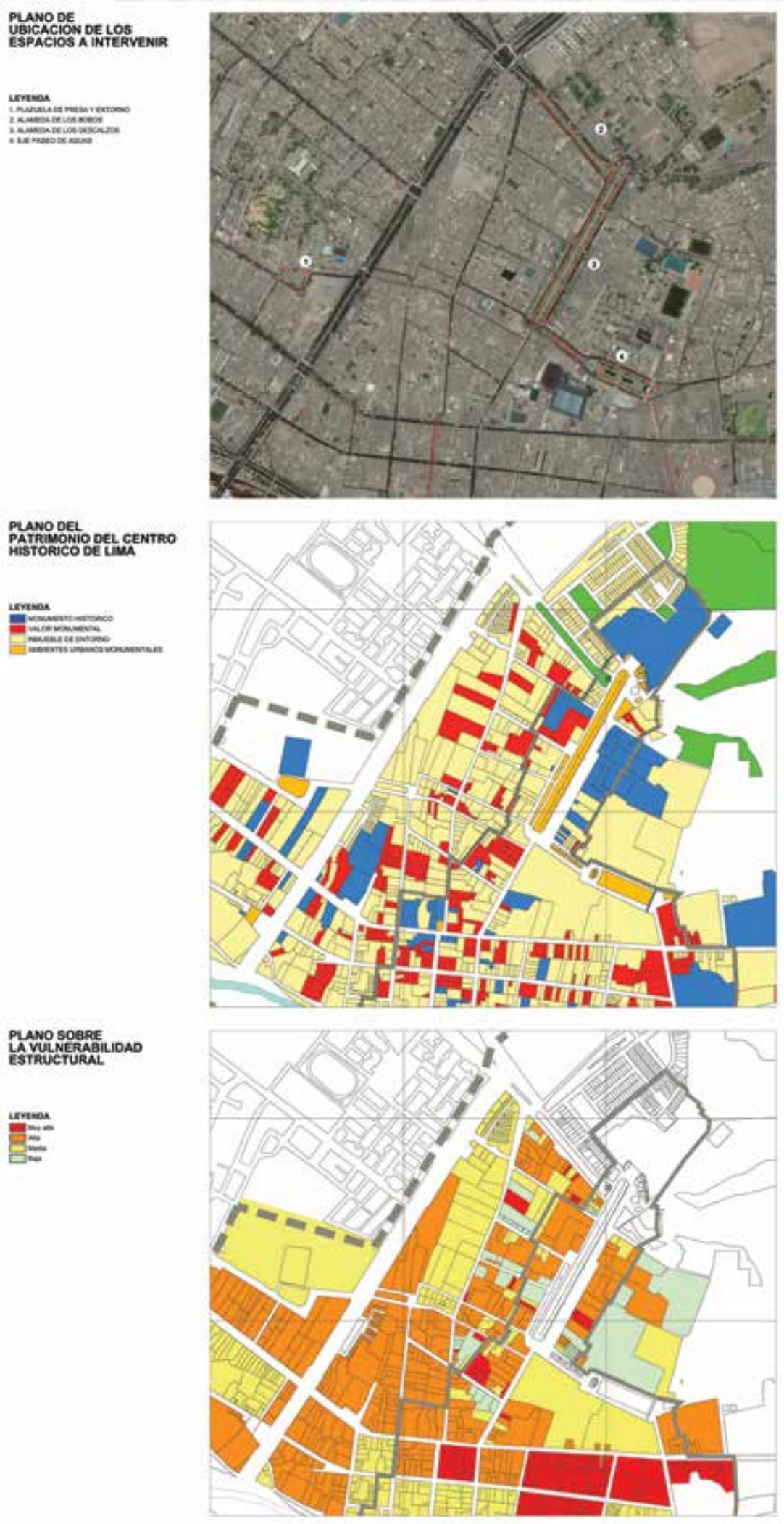

Figura 14. Escenarios de intervención en el concurso de ideas para el Rímac. Su relación patrimonial y su vulnerabilidad estructural. En Plan Maestro para el Centro Histórico de Lima al 2025 (pp. 34 y 78), por Municipalidad Metropolitana de Lima, 2014 
devenir Vol. 5, №10, JULIO - DICIEMBRE 2018, PP. 109-134 - EstudIOS | ISSN 2312-7562 | E-ISSN 2616-4949

UNIVERSIDAD NACIONAL DE INGENIERÍA, LIMA

DOI: https://doi.org/10.21754/devenir.v5i10.601

\section{LEYENDA}

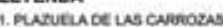

2 PURUEL Sunth CUNA

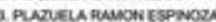

The

\section{PLANO DE \\ UBICACION DE LOS ESPACIOS A INTERVENIR}

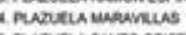

\section{PLANO DEL \\ PATRIMONIO DEL CENTRO HISTORICO DE LIMA}

\section{LEYENDA \\ - vongaubro restonico \\ vMEOR MONENENTAN \\ INAVUedRe De ENTOPEN \\ MMEsevits ungawos Monumentaes}
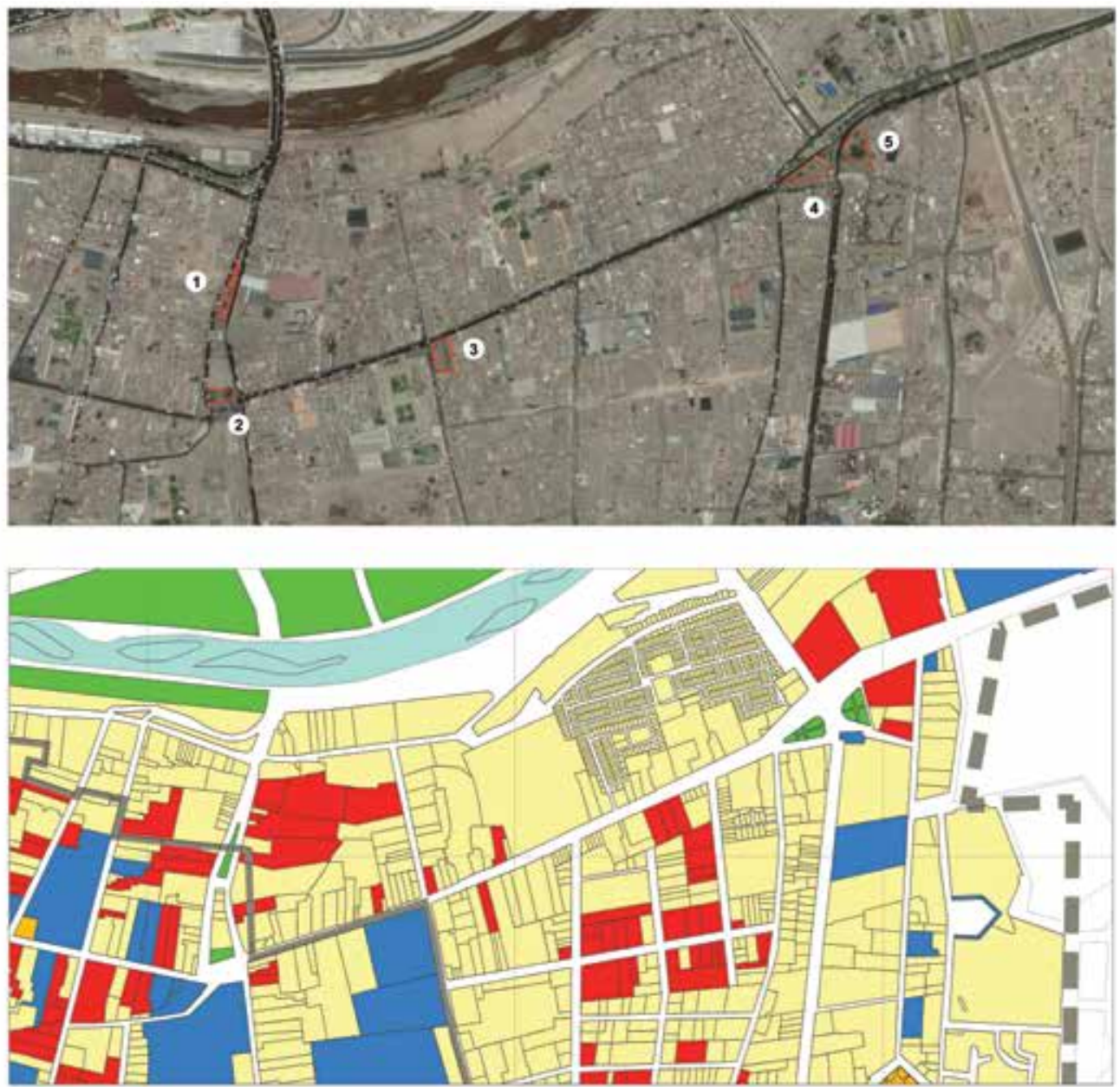

\section{PLANO SOBRE LA VULNERABILIDAD ESTRUCTURAL}

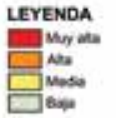

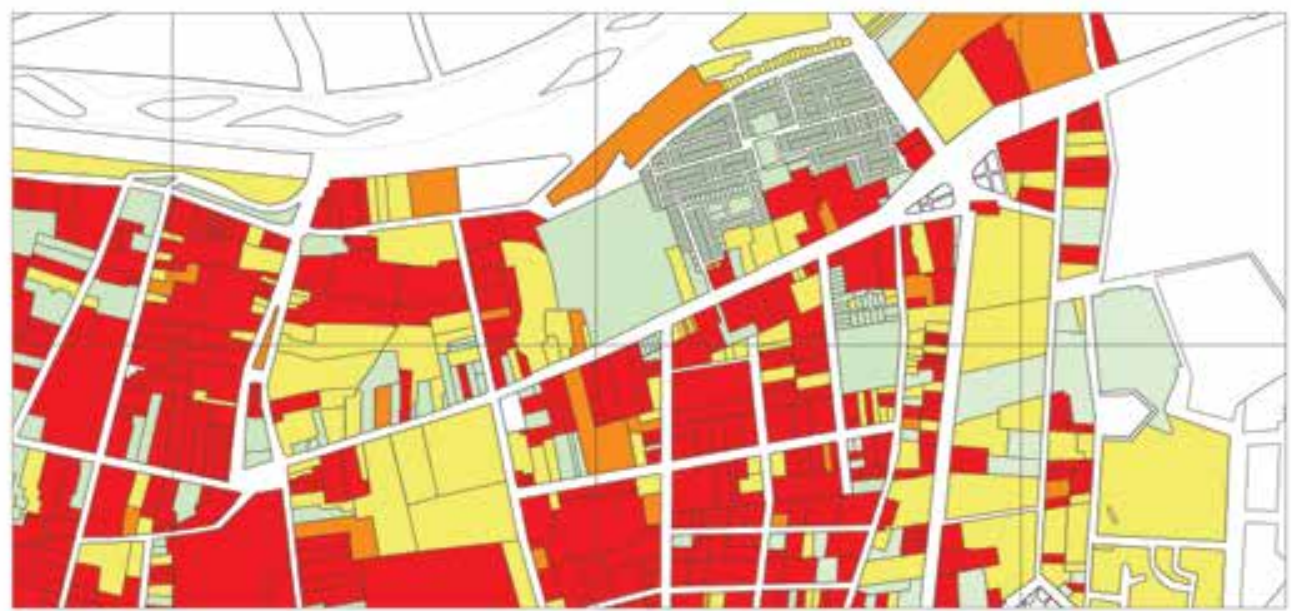

Figura 15. Escenarios de intervención en el concurso de ideas para el Jr. Ancash. Su relación patrimonial y su vulnerabilidad estructural. En Plan Maestro para el Centro Histórico de Lima al 2025, (pp. 34 y 78), por Municipalidad Metropolitana de Lima, 2014. 
Tabla 2. Matriz de entrevistas y preguntas sobre el impacto de la intervención de la Cooperación Española en el Centro Histórico de Lima. Elaboración propia.

\begin{tabular}{|c|c|c|c|c|c|c|c|c|c|c|}
\hline $\begin{array}{l}\text { MARCO } \\
\text { HUMANO }\end{array}$ & $\begin{array}{c}\text { Relación } \\
\text { dentro } \\
\text { del marco } \\
\text { bilateral } \\
\text { Perú-Espa- } \\
\text { ña }\end{array}$ & $\begin{array}{l}\text { Evolu- } \\
\text { ción de la } \\
\text { relación } \\
\text { bilateral } \\
\text { Perú-Espa- } \\
\text { ña }\end{array}$ & $\begin{array}{l}\text { Relación } \\
\text { P y D en } \\
\text { el medio } \\
\text { nacional } \\
\text { ajenos al } \\
\text { programa }\end{array}$ & $\begin{array}{l}\text { Impacto } \\
\text { de la Coo- } \\
\text { peración } \\
\text { Española } \\
\text { (1 a 5) }\end{array}$ & $\begin{array}{l}\text { Dimensión } \\
\text { que fue la } \\
\text { más sobre- } \\
\text { saliente }\end{array}$ & $\begin{array}{c}\text { Etapas de la } \\
\text { Cooperación } \\
\text { Española } \\
\text { entre 1990- } \\
2013\end{array}$ & $\begin{array}{l}\text { Trabajos } \\
\text { representa- } \\
\text { tivos en el } \\
\text { CH de Lima }\end{array}$ & $\begin{array}{l}\text { Nivel de } \\
\text { desarrollo } \\
\text { en el CH de } \\
\text { Lima tras el } \\
\text { programa }\end{array}$ & $\begin{array}{c}\text { Rol del } \\
\text { estado } \\
\text { peruano } \\
\text { dentro de } \\
\text { la coopera- } \\
\text { ción }\end{array}$ & $\begin{array}{l}\text { Que factor } \\
\text { no funciono } \\
\text { bien y de } \\
\text { cambiarse } \\
\text { se logra } \\
\text { un mayor } \\
\text { impacto }\end{array}$ \\
\hline $\begin{array}{l}\text { Arq. Juan } \\
\text { de la Serna } \\
\text { Torroba }\end{array}$ & $\begin{array}{l}\text { Director del } \\
\text { programa } \\
\mathrm{P}>\mathrm{D}\end{array}$ & $\begin{array}{l}\text { Siempre } \\
\text { fueron bue- } \\
\text { nas a pesar } \\
\text { de las crisis } \\
\text { políticas }\end{array}$ & $\begin{array}{l}\text { No existía } \\
\text { visión o un } \\
\text { plan, menos } \\
\text { especialza- } \\
\text { ción en el } \\
\text { patrimonio }\end{array}$ & $\begin{array}{l}\text { Marco } \\
\text { general de } \\
3.5 \text { a } 4\end{array}$ & $\begin{array}{l}\text { En todas sus } \\
\text { dimensiones } \\
\text { logra un } \\
\text { desarrollo } \\
\text { medio alto } \\
\text { (4) }\end{array}$ & $\begin{array}{l}\text { 1989-2000: } \\
\text { Intervención } \\
\text { directa "Etapa } \\
\text { patrimonialista” } \\
\text { 2000-2013: } \\
\text { Concursosy } \\
\text { apuesta por } \\
\text { el espacio } \\
\text { público, “Etapa } \\
\text { proyectista” }\end{array}$ & $\begin{array}{l}\text { Escuelta Ta- } \\
\text { ller de Lima } \\
\text { Casona de } \\
\text { San Marcos } \\
\text { Casa Aspi- } \\
\text { llaga }\end{array}$ & $\begin{array}{l}\text { El programa } \\
\text { logro un éxi- } \\
\text { to parcial, se } \\
\text { trabajo pero } \\
\text { no se logro } \\
\text { lo esperado }\end{array}$ & $\begin{array}{l}\text { Menos de } \\
\text { lo esperado, } \\
\text { muchas } \\
\text { veces obsta- } \\
\text { culizador }\end{array}$ & $\begin{array}{l}\text { Estado tra- } \\
\text { duzca el apo- } \\
\text { yo en mayor } \\
\text { planeamiento } \\
\text { territorial y } \\
\text { presupuesto }\end{array}$ \\
\hline $\begin{array}{l}\text { Arq. Martin } \\
\text { Fabbri }\end{array}$ & $\begin{array}{l}\text { Coope- } \\
\text { rante en la } \\
\text { intervención } \\
\text { de la Casona } \\
\text { San Marcos } \\
\text { como parte } \\
\text { del equipo } \\
\text { de la univer- } \\
\text { sidad. }\end{array}$ & $\begin{array}{l}\text { No fue una } \\
\text { relación } \\
\text { lineal, el } \\
\text { apoyo no } \\
\text { siempre fue } \\
\text { constan- } \\
\text { te,hubieron } \\
\text { altos y bajos. }\end{array}$ & $\begin{array}{l}\text { Se intervenía } \\
\text { como una } \\
\text { especie de } \\
\text { mecenazgo, } \\
\text { de benefi- } \\
\text { ciencia }\end{array}$ & $\begin{array}{l}\text { En todas } \\
\text { sus di- } \\
\text { mensiones } \\
\text { logra tras- } \\
\text { cendencia. }\end{array}$ & $\begin{array}{l}\text { En todas sus } \\
\text { dimensiones } \\
\text { logra un } \\
\text { desarrollo } \\
\text { medio (3) }\end{array}$ & $\begin{array}{l}\text { 1990-2000: } \\
\text { Intervenciones } \\
\text { de emergencia } \\
\text { dentro de la } \\
\text { casona 2000- } \\
\text { 2008: Apoyo } \\
\text { en modelo de } \\
\text { gestión del } \\
\text { centro cultural }\end{array}$ & $\begin{array}{l}\text { Casona de } \\
\text { San Marcos }\end{array}$ & $\begin{array}{l}\text { Si logra } \\
\text { acompañar } \\
\text { el proceso } \\
\text { de desarrollo } \\
\text { del centro } \\
\text { histórico }\end{array}$ & $\begin{array}{l}\text { No era } \\
\text { participativo, } \\
\text { ni tenía ini- } \\
\text { ciativa, solo } \\
\text { en al etapa } \\
\text { final de cada } \\
\text { intervención }\end{array}$ & $\begin{array}{l}\text { Atender la } \\
\text { cooperación } \\
\text { como } 1 \text { a } 1 \\
\text { desde ahora, } \\
\text { equidad de } \\
\text { responsabili- } \\
\text { dades }\end{array}$ \\
\hline $\begin{array}{l}\text { Arq. Mirna } \\
\text { Soto Me- } \\
\text { dina }\end{array}$ & $\begin{array}{l}\text { Docente de } \\
\text { la Escuela } \\
\text { Taller de } \\
\text { Lima }\end{array}$ & $\begin{array}{l}\text { Siempre } \\
\text { fueron bue- } \\
\text { nas a pesar } \\
\text { de las crisis } \\
\text { políticas }\end{array}$ & $\begin{array}{l}\text { Momento de } \\
\text { crisis, nadie } \\
\text { se le ocurriría } \\
\text { apostar por } \\
\text { el patrimo- } \\
\text { nio histórico }\end{array}$ & $\begin{array}{l}\text { En dos mo- } \\
\text { mentos. } \\
\text { 1990-2000: } 4 \\
\text { 2000-2013: } 2\end{array}$ & $\begin{array}{l}\text { Dimensión } \\
\text { cultural y so- } \\
\text { cial, debido } \\
\text { a las inter- } \\
\text { venciones y } \\
\text { a la Escuela } \\
\text { Taller }\end{array}$ & $\begin{array}{l}\text { 1990-2006: } \\
\text { Financiador de } \\
\text { intervenciones } \\
\text { en patrimonio } \\
\text { 2006-2013: En- } \\
\text { foque en que } \\
\text { los proyectos } \\
\text { sean autoges- } \\
\text { tionados }\end{array}$ & $\begin{array}{l}\text { Como obra: } \\
\text { Casona de } \\
\text { San Marcos } \\
\text { Como ges- } \\
\text { tión: Escuela } \\
\text { Taller de } \\
\text { Lima }\end{array}$ & $\begin{array}{l}\text { Si se logro } \\
\text { un nivel de } \\
\text { desarrollo al } \\
\text { apostar por } \\
\text { la población } \\
\text { vulnerable }\end{array}$ & $\begin{array}{l}\text { No era } \\
\text { participativo, } \\
\text { ni tenía ini- } \\
\text { ciativa, solo } \\
\text { en al etapa } \\
\text { final de cada } \\
\text { intervención }\end{array}$ & $\begin{array}{l}\text { Mayor apoyo } \\
\text { gerencial de } \\
\text { la contraparte } \\
\text { peruana, brin- } \\
\text { dar respaldo a } \\
\text { lo programas } \\
\text { de capacita- } \\
\text { ción }\end{array}$ \\
\hline $\begin{array}{l}\text { Arq. Patricia } \\
\text { Dias Velarde }\end{array}$ & $\begin{array}{l}\text { Contraparte } \\
\text { peruana } \\
\text { desde el } \\
\text { Instituto } \\
\text { Nacional de } \\
\text { Cultura }\end{array}$ & $\begin{array}{l}\text { Relativamen- } \\
\text { te buena, } \\
\text { España } \\
\text { invierte en el } \\
\text { Perú }\end{array}$ & $\begin{array}{l}\text { No existia, } \\
\text { nadie } \\
\text { invertía en } \\
\text { la puesta } \\
\text { en valor del } \\
\text { patrimonio }\end{array}$ & $\begin{array}{l}\text { Marco ge- } \\
\text { neral de } 3\end{array}$ & $\begin{array}{l}\text { Dimensión } \\
\text { cultural-pa- } \\
\text { trimonial por } \\
\text { hacer inter- } \\
\text { venciones }\end{array}$ & $\begin{array}{l}\text { 1990-2005: } \\
\text { Mayor } \\
\text { impacto, más } \\
\text { presencia en el } \\
\text { centro históri- } \\
\text { co 2005-2013: } \\
\text { Desapercibido } \\
\text { del panorama } \\
\text { de acciones } \\
\text { en el centro } \\
\text { histórico }\end{array}$ & $\begin{array}{l}\text { Casona de } \\
\text { San Marcos }\end{array}$ & $\begin{array}{l}\text { Desarrollo } \\
\text { parcial, pues } \\
\text { en el aspecto } \\
\text { social pudo } \\
\text { lograr un } \\
\text { mayor } \\
\text { impacto. }\end{array}$ & $\begin{array}{l}\text { Menos de } \\
\text { lo esperado, } \\
\text { muchas } \\
\text { veces obsta- } \\
\text { culizador }\end{array}$ & $\begin{array}{l}\text { Apoyo } \\
\text { institucional, } \\
\text { inclusión de } \\
\text { las activida- } \\
\text { des de la coo- } \\
\text { peración con } \\
\text { el gobierno } \\
\text { local }\end{array}$ \\
\hline $\begin{array}{l}\text { Arq. José } \\
\text { Correa } \\
\text { Orbegoso }\end{array}$ & $\begin{array}{l}\text { Asesor del } \\
\text { director de } \\
\text { patrimonio } \\
\text { del Instituto } \\
\text { Nacional de } \\
\text { Cultura }\end{array}$ & $\begin{array}{l}\text { Relativamen- } \\
\text { te buena, } \\
\text { España } \\
\text { invierte en el } \\
\text { Perú }\end{array}$ & $\begin{array}{l}\text { En general } \\
\text { no exístia } \\
\text { alguna rela- } \\
\text { ción, salvo } \\
\text { uno que } \\
\text { otro caso, no } \\
\text { había mayor } \\
\text { inversión }\end{array}$ & $\begin{array}{l}\text { Marco ge- } \\
\text { neral de } 3\end{array}$ & $\begin{array}{l}\text { Dimensión } \\
\text { cultural-pa- } \\
\text { trimonial por } \\
\text { hacer inter- } \\
\text { venciones }\end{array}$ & $\begin{array}{l}\text { No identifica } \\
\text { etapas, todas } \\
\text { sus interven- } \\
\text { ciones son } \\
\text { aleatorias y } \\
\text { no obedecen } \\
\text { a un plan en } \\
\text { general }\end{array}$ & $\begin{array}{l}\text { Casona de } \\
\text { San Marcos } \\
\text { Casa Aspi- } \\
\text { llaga }\end{array}$ & $\begin{array}{l}\text { No, obras } \\
\text { aleatorias } \\
\text { que no tras- } \\
\text { cienden en } \\
\text { la magnitud } \\
\text { del centro }\end{array}$ & $\begin{array}{l}\text { Se vivía una } \\
\text { crisis institu- } \\
\text { cional en el } \\
\text { INC, que no } \\
\text { apoyo a la } \\
\text { cooperación }\end{array}$ & $\begin{array}{l}\text { La direc- } \\
\text { ción de la } \\
\text { cooperación } \\
\text { española, un } \\
\text { director más } \\
\text { inclusivo y } \\
\text { participativo }\end{array}$ \\
\hline
\end{tabular}



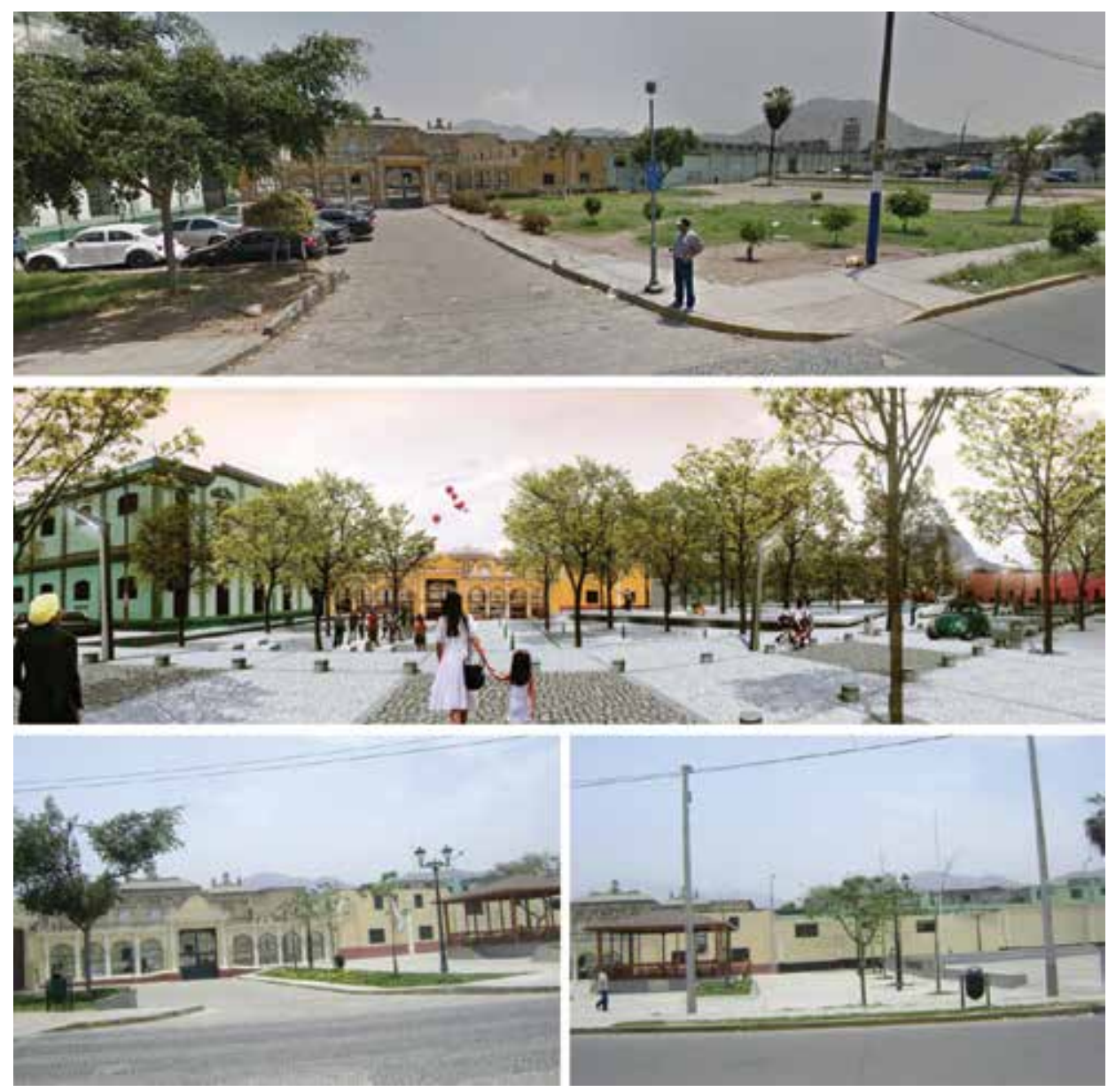

Figura 16. Comparativo de la plazuela de la Quinta de Presa antes de su intervención, la propuesta ganadora y finalmente lo inaugurado por el municipio en el 2014. Google Street View, 2013; AECID, 2015c, p. 59; y fototeca de Miguel Visurraga, recuperado de http://miguel42oo.blogdiario.com/1439074830/ centro-historico-del-rimac-quinta-de-presa/

\section{Reflexiones sobre el impacto de la Cooperación Española}

Para evaluar el impacto del programa en el medio peruano, un equipo de profesionales ha calificado, según su criterio, sus principales fortalezas y debilidades, mediante una escala de calificaciones que va del uno (1) al cinco (5), a la que corresponden respectivamente las categorías baja, media baja, media, media alta y alta (Tabla 2).

El equipo de profesionales estableció que hubo buenos resultados en general, un apoyo con ciertos altos y bajos, pero que se mantuvo constante. También concuerdan que en el medio local no hubo una adecuada relación entre las intervenciones en el patrimonio y el potencial desarrollo que podrían haber generado estas actuaciones, debido a la crisis que las instituciones nacionales atravesaban en ese entonces -sostienen algunos-, pues no se hacían propuestas de recuperación de inmuebles patrimoniales. De acuerdo a una calificación prorrateada, se logró un impacto medio (3) a medio alto (4). Cabe mencionar que los trabajos de cooperación mutua no siempre fueron abordados con la misma responsabilidad. Asimismo, la crisis que se vivía y el recelo profesional hizo que estos trabajos no tuvieran el impacto deseado. La mayoría de expertos consultados reconocen etapas, y si bien los rangos entre los que se identifican estas etapas son variados, concuerdan en que durante la primera década la 

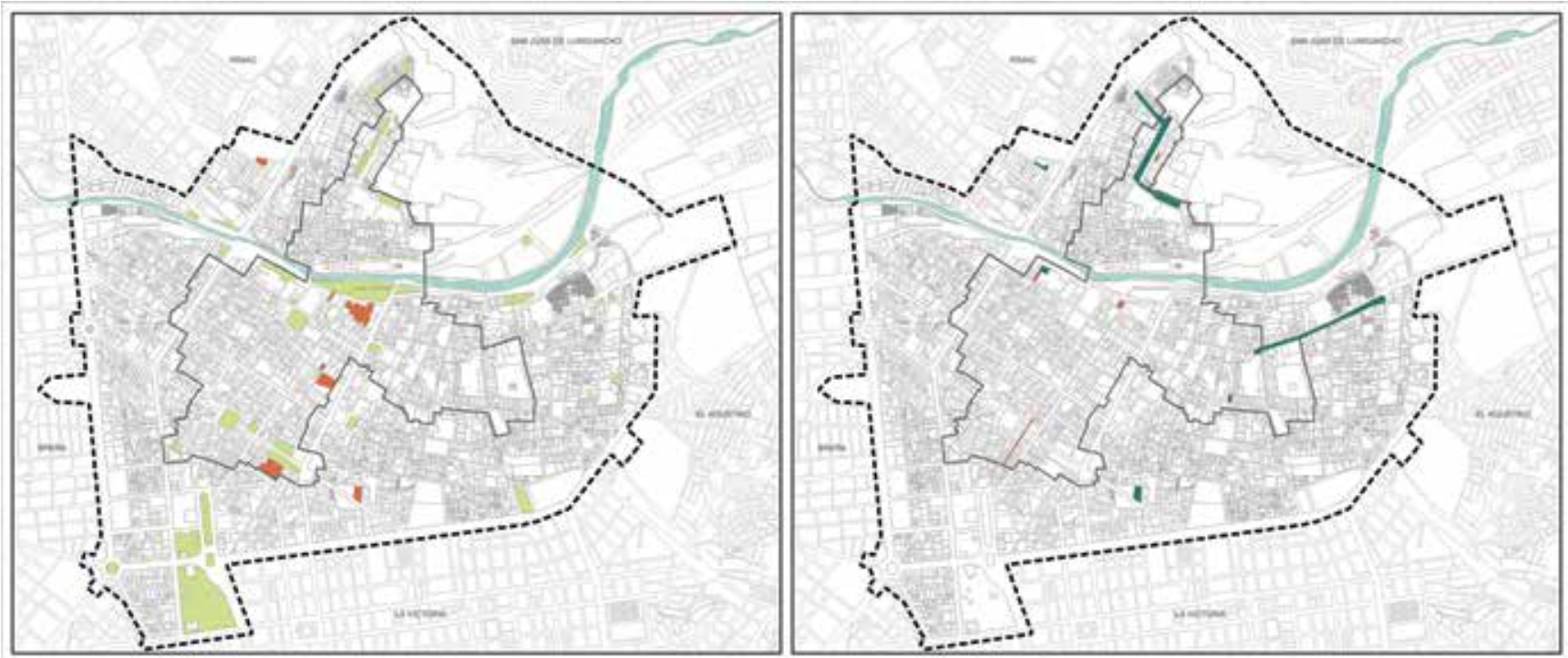

presencia de la Cooperación Española fue mayor, y que entonces se desarrolló el grueso de sus intervenciones. La Casona de San Marcos, así como la Casa Aspillaga, ambas actualmente centros culturales, son ahora las obras más representativas del trabajo de la Cooperación Española. Finalmente, la mayoría indica que el rol del Estado peruano en la relación bilateral fue mayormente obstaculizador.

El director del programa, el Arq. Juan de La Serna Torroba, manifiesta que el mayor impacto ha tenido lugar en el ámbito de la sensibilización, el lograr poner en agenda el tema cultural:

Creo que lo que se ha logrado en estos tiempos es sensibilizar a la gente sobre el patrimonio. Es un logro importantísimo: ya nadie es indiferente ante el patrimonio... Salió la gente, los estudiantes de arquitectura a defender la ciudad, a defender el patrimonio, el legado contemporáneo. También hemos contribuido a hacer presente en muchas personas -no en todas- la importancia del patrimonio, porque es parte de lo que tú eres, tu legado, tu historia. (J. De la Serna Torroba, comunicación personal, 14 de noviembre de 2016)

Según Mirna Soto Medina, exdirectora de la Escuela Taller de Lima, las razones por las que no se llegó a tener el impacto deseado con estos centros educativos y no se logró la acreditación por parte del Estado Peruano son las siguientes:

Las cabezas son las que te conducen. Si hablamos solamente de la escuela, yo pienso que la dirección.... debió haber afrontado una nueva etapa, incorporando personas con formación gerencial. Al principio funcionó, porque necesitabas gente que supiese de restauración, que pudiese organizar una escuela, en la parte académica. Pero cuando todo eso ya estuvo funcionando, necesitabas algo más: personas con otra proyección. Creo que ya se habían acostumbrado a un ritmo que marchaba bien y se quedaron con él. No se adecuaron a una nueva época. (Comunicación personal, 21 de noviembre de 2016)

Por su parte, la Arq. Patricia Días Velarde sostiene que un desacierto de la cooperación fue no trabajar en conjunto con el Gobierno local:

La Cooperación Española no apoyó directamente a la municipalidad en todo el proceso de trabajo de recuperación del patrimonio, a pesar de que se solicitó, porque ellos también hubieran podido ayudar con el plan urbano del centro. En algún momento se pidió que nos apoyaran. Su respuesta fue "nosotros no apoyamos a gobiernos locales, solamente po-
Figura 17. Etapas de la Cooperación en Lima: la primera, netamente intervencionista; y la segunda, de recuperación de espacios públicos y trabajos de conservación.

Elaboración propia. 
devenir Vol. 5, N¹0, JULIO-DICIEMBRE 2018, PP. 109-134 - EsTUdIOS | ISSN 2312-7562 | E-ISSN 2616-4949

UNIVERSIDAD NACIONAL DE INGENIERÍ, LIMA

DOI: https://doi.org/10.21754/devenir.v5i10.601

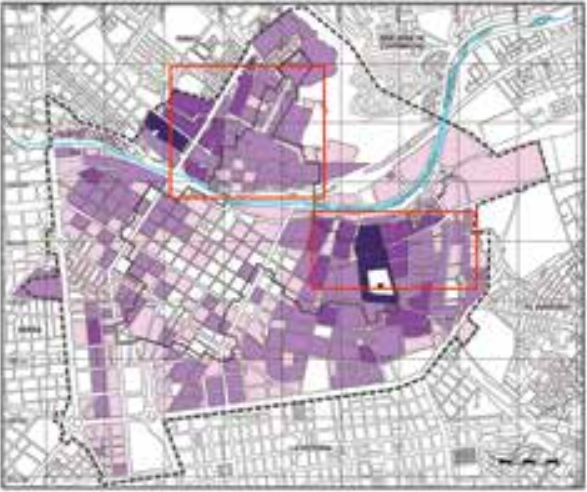

PLANO DE LA POBLACION CON AL

MENOS UNA DISCAPACIDAD

LETENon

$\square^{0-10}$

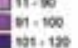

Figura 18. Vulnerabilidad social en el Centro Histórico de Lima.

En los marcos se evidencian las zonas de actuaciones de los concursos de ideas. En Plan Maestro para el Centro Histórico de Lima al 2025 (pp. 80-81), por Municipalidad Metropolitana de Lima, 2014.
VULNERABILIDAD SOCIAL

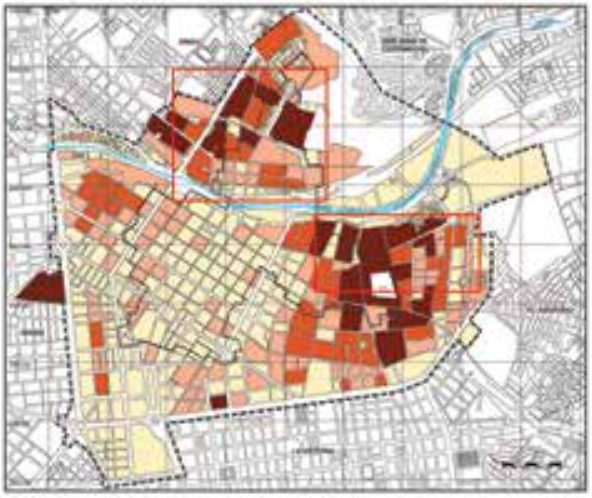

PLANO DE LA POBLACION MAYOR

DE 65 ANNOS

IEYENDA

$\prod_{\substack{0+20 \\ 21+30}}^{0+100}$

$21+80$
$5 x+100$

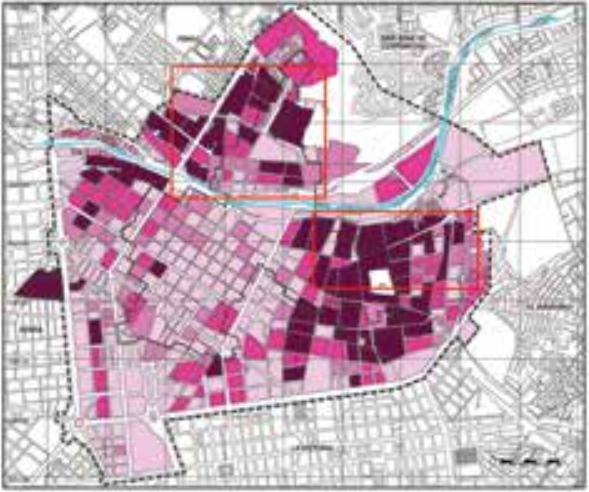

PLANO DE LA POBLACION MAYOR DE 65 ANNOS

LEYrenan

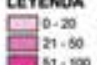

$\operatorname{lin}_{s 1+\infty}=00$

demos apoyar al gobierno nacional", y al haber un problema muy serio entre el gobierno nacional y el gobierno local... ellos no quisieron comprometerse con la administración local. Ahí me parece que pudieron hacer un esfuerzo y tratar de apoyar. (Comunicación personal, 28 de noviembre de 2016)

A su vez, el Arq. José Correa Orbegoso, asesor del director de patrimonio del INC, menciona de manera contundente que el mayor impacto de las labores de la Cooperación Española fue la recuperación de inmuebles patrimoniales como la Casona de San Marcos. No reconoce ninguna trascendencia del aspecto social del programa.

\section{Conclusiones}

Si bien en general las relaciones bilaterales entre Perú y España fueron mejorando con el pasar del tiempo, tuvo lugar un cambio significativo tras la creación del Instituto de Cultura Hispánica, organismo que operó siguiendo la premisa de que la historia compartida es aquello que debe permitir mejorar y afianzar las relaciones entre ambos Estados. Inicialmente el trabajo del ICH se centró en el ámbito netamente cultural, pero tras la caída del gobierno franquista se fusionaron este y otros organismos, con lo que a esta política exterior se le sumaron otras dimensiones. Así, se creó la Agencia Española de Cooperación Internacional, institución que inició el programa Patrimonio para el Desarrollo en el Perú, y que años después se convertiría en la Agencia Española de Cooperación Internacional para el Desarrollo.

Antes de que se iniciase dicho programa, cuando la Cooperación Española inició sus labores en Lima, no se realizaban intervenciones de puesta en valor de patrimonio desde la perspectiva de recuperarlos para la ciudad: se trataba de casos aislados de restauraciones que no obedecían a ninguna política, sino a iniciativas particulares. En ese sentido, el programa fue pionero.

En el Perú, la principal actuación que ha tenido la Cooperación Española es la intervención directa en monumentos históricos (restauración, conservación, puesta en valor). En escenarios en los que el programa ha participado una o dos veces, ha optado primero por la restauración y, en segundo lugar, por facilitar apoyo institucional, como ocurrió en el caso de los planes locales de desarrollo. 
En el caso de Lima, el $72 \%$ de las intervenciones que ha realizado la Cooperación Española en la ciudad, han tenido lugar en el Centro Histórico, las cuales se encuentran concentradas en la zona nombrada Patrimonio Cultural de la Humanidad por UNESCO. La Escuela Taller de Lima ha colaborado en el 67 \% de las intervenciones directas llevadas a cabo en la ciudad.

Respecto al funcionamiento del programa, cabe mencionar que su presencia no ha sido continua, sino que es posible identificar dos etapas: una primera, que puede ser llamada patrimonialista (1990-2004), durante la cual se iniciaron la mayoría de las intervenciones de restauración integral, como la casona de San Marcos y la Casa Aspillaga, sus obras más representativas; y una segunda, la etapa de gestión (2005-2013), durante la que se siguieron los trabajos de recuperación pero considerando el factor de gestión, necesario para dar sostenibilidad al proceso. Durante esta segunda etapa, por ejemplo, se llevó a cabo la primera intervención en un ambiente urbano monumental y se iniciaron concursos de recuperación de espacios públicos (Figura 17).

En el medio nacional, la crisis interna que atravesaban las instituciones nacionales en la década de 1990 afectó las relaciones con la Cooperación Española, debido a que en muchos casos el rol del Estado se volvió un obstáculo. Al no contar con el apoyo de las instituciones estatales, las intervenciones de la Cooperación no pudieron articularse dentro de un plan de recuperación integral del Centro Histórico. Durante la primera etapa, las intervenciones más directas y de mayor consideración no se llevaron a cabo en coordinación con el Gobierno, como parte de un plan integrador. Por otra parte, en la segunda etapa, la Cooperación propuso ideas para revitalizar los espacios públicos del Centro Histórico de Lima, y escogió las zonas más vulnerables socialmente para trabajar. Así, empleó sus recursos para la difusión de un plan catalizador de oportunidades a través de la recuperación de estos ambientes urbanos monumentales (Figura 18).

Para los profesionales entrevistados, la dimensión que tuvo mayor trascendencia fue la cultural-patrimonial: las obras recuperadas en el Centro Histórico, la Casona de San Marcos y la Casa Aspillaga. Este lineamiento cultural-patrimonial de la Cooperación Española se hace evidente en sus trabajos en el interior del país, donde optó por recuperar edificios representativos y transferirlos a la comunidad, en algunos casos con un nuevo uso. Por otro lado, los mismos profesionales señalan que la dimensión institucional tuvo menor relevancia debido a la crisis que atravesaba el Gobierno.

En conclusión, gracias la implementación del programa se obtuvo un desarrollo parcial, pues al tratarse de un trabajo de cooperación mutua, la inacción de la contraparte peruana, debido a la crisis en la que se encontraba inmersa, y su ausencia de apoyo institucional tuvo un impacto negativo en el proceso de las actuaciones. El programa de la Cooperación Española acompañó otros procesos en el desenvolvimiento del Centro Histórico: generó las ET como brazo ejecutor de las actividades de restauración, las cuales se abocaron por completo hacia la instrucción de población vulnerable. Estas pueden señalarse como el mayor éxito del programa, pues a pesar de sus carencias fueron la mejor apuesta de la Cooperación en el Centro Histórico.

\section{Referencias}

Agencia Española de Cooperación Internacional para el Desarrollo. (2006). P>D Patrimonio para el Desarrollo. Programa de Patrimonio de la Cooperación Española. Nueva Etapa. Madrid, España: Autor.

Agencia Española de Cooperación Internacional para el Desarrollo. (2007). Las Escuelas Taller en su laberinto: Nuevos enfoques y desafíos. Recuperado de http://www.aecid.es/Centro-Documentacion/Documentos/Publicaciones\%20coeditadas\%20por\%20AECID/las_eett_en_su_ laberinto.pdf 
devenir Vol. 5, N¹0, JULIO-DICIEMBRE 2018, PP. 109-134 - EstUdIOS I ISSN 2312-7562 I E-ISSN 2616-4949 UNIVERSIDAD NACIONAL DE INGEEIERÍA, LIMA

DOI: https://doi.org/10.21754/devenir.v5i10.601

Agencia Española de Cooperación Internacional para el Desarrollo. (2012). Proyectos Perú 19902011. Lima, Perú: Autor.

Agencia Española de Cooperación Internacional para el Desarrollo. (2015a). 25 años cooperando con América Latina y el Caribe. Madrid, España: Autor.

Agencia Española de Cooperación Internacional para el Desarrollo. (2015b). Programa de Escuelas Taller de la Cooperación Española. Madrid, España: Autor.

Agencia Española de Cooperación Internacional para el Desarrollo. (2015c). Concurso de ideas Rímac: Espacios públicos. Lima, Perú:Autor

Bonilla, P. (2015). Praxis en el pasado: Aproximaciones a la intervención en el patrimonio arquitectónico de Lima. Devenir, 2(3), 45-62.

Burneo, R. (2013). Orígenes y evolución del conjunto arquitectónico de la Casona de San Marcos. Lima, Perú: Agencia Española de Cooperación Internacional para el Desarrollo.

Calleja, E. G. (1994). El servicio exterior de Falange y la política exterior del primer Franquismo: Consideraciones previas para su investigación. Hispania, LIV (186), 279-307.

Cañellas, A. (febrero, 2014). Las políticas del Instituto de Cultura Hispanica 1947-1953. Historia Actual Online, (33), 77-91.

Frischlander, A. (1968). Perú. Restauración de la Universidad de San Marcos de Lima. París, Francia: Organización de las Naciones Unidas para la Educación, la Ciencia y la Cultura.

Heinz, K. W. (1997). Lima: Ayer y hoy. Lima, Perú: Municipalidad Metropolitana de Lima.

Instituto de Cultura Hispánica. (1953). El Instituto de Cultura Hispánica al servicio de lberoamérica. Madrid, España: Gobierno de España.

Larrea Tovar, J. (2015). Lima: Patrimonio, tierra y comunidad (secuencia de diapositivas). Recuperado de https://es.slideshare.net/mariohidrobo/lima-patrimonio-tierra-y-comunidad).

Municipalidad Metropolitana de Lima. (2014). Plan Maestro para el Centro Histórico de Lima al 2025. Recuperado de www.munlima.gob.pe/images/descargas/licencias-de-edificaciones/ legislacion/ORD-062-Reg-de-la-administ-del-CHL.pdf

Ministerio de Cultura (2018). Lista de Patrimonio Histórico Inmueble. Recuperado de www.cultura. gob.pe/es/serviciosenlinea/patrimoniohistoricoinmueble).

Navarro, C. N. (2011). La casa matriz del sueño hispánico: El Colegio Mayor Nuestra Señora de Guadalupe 1947-2009. Recuperado de http://eprints.ucm.es/14063/1/C_M_Guadalupe\%5B1\%5D.pdf

Novak, F. (2001). Las relaciones entre el Perú y España (1821-2000). Lima, Perú: Pontificia Universidad Católica del Perú.

Gunther, J. (1992). Jornadas de Lima. Lima, Perú: Patronato de Lima,

Rosa, J. (1947). Misión y tarea del Instituto de Cultura Hispánica. Revista de Educación, (70). Recuperado de http://www.mecd.gob.es/dctm/revista-de-educacion/1947/194770/1947re70obra03.pdf?documentld=0901e72b81ee466f 